\title{
Assessing Wind Data from Reanalyses for the Upper Midwest
}

\author{
JACOB J. COBURN \\ Department of Geography, Environment and Society, University of Minnesota, Twin Cities, Minneapolis, Minnesota
}

(Manuscript received 21 June 2018, in final form 2 January 2019)

\begin{abstract}
Wind is an important atmospheric variable that is receiving increased attention as the world seeks to shift from carbon-based fuels in order to mitigate climate change. This has resulted in increased need for more temporally and spatially continuous wind information, which is often met through the use of reanalysis data. However, limited work has been done to assess the long-term accuracy of the wind data against observations in the context of specific applications. This study focuses on the representation of daily and monthly average 10-m wind speed data in the upper Midwest by six global reanalysis datasets. The accuracy of the datasets was assessed using several measures of skill, as well as the associated wind speed distributions and long-term trends. While it was found that higher resolution and complexity in more recent generations of reanalyses produced more accurate simulations of wind in the region, important biases remained. High variability in the observed data resulted in lower correlations at the monthly time scale. As with previous research, linear trends calculated from the reanalyzed wind speeds were significantly underestimated compared to observed trends. While it is expected that future improvements in model resolution, physics, and data assimilation will further improve wind representation in reanalyses, accounting for the differences between the available datasets and their associated biases will be important for potential applications of the output, particularly wind resource assessment.
\end{abstract}

\section{Introduction}

Wind is an important factor in local and regional weather patterns yet has only recently been more robustly analyzed as the demand for wind information has grown (Clark et al. 2017). Research into the climatology and variability of wind over several time scales is informative to many applications such as wind energy planning (Carta et al. 2013), hydrology (Krogh et al. 2015), and modeling the spread of aerosols and atmospheric pollutants (Cheng et al. 2016). Short-term, subdaily wind predictability has improved significantly in the last few decades, which has been of importance to energy suppliers who must carefully balance the intermittent power supply against fast-paced changes in demand (Clark et al. 2017; Jung and Broadwater 2014). Long-term wind assessments, however, while necessary for many of these efforts, are hampered by the lack of wind data coverage that are of sufficient duration for the task. Nearby stations can provide long wind records in some locations and have been used as wind proxies for site-specific projects, though they are spatially and

Corresponding author: Jacob J. Coburn, cobur018@umn.edu temporally discontinuous and suffer from inhomogeneities caused by changes in instrumentation and station placement, as well as nearby environmental changes that affect local wind flow (Wan et al. 2010; Pirazzoli and Tomasin 2003; Lott and Baldwin 2002).

One source of long-term wind data is retrospective analyses, or reanalyses. These models produce spatially and temporally complete datasets that aim to capture the true state of the atmosphere over several decades by assimilating observations. The gridded data provide continuous output over the surface and throughout the atmosphere, including places rarely if ever sampled by observational networks. Reanalyzed datasets come with their own uncertainties stemming from biases in the observations and model parameterizations, the integration processes used to assimilate the data, and the output of continuous atmospheric variables into discreet grid points (Parker 2016; Wang et al. 2016; Rose and Apt 2015). To extract information for specific locations unresolved by the model grids and estimate the uncertainties of the model output, data from grid cells in the model output can be interpolated to those locations or used as a predictor variable in a statistical model constructed to estimate the relationship between the 
decades-long reanalysis time series and shorter-term data collected at a location of interest. This is the basis of long-term wind resource estimation methods such as the measure-correlate-predict (MCP) procedure (Carta et al. 2013) or the analog ensemble approach (Vanvyve et al. 2015). These methods of site-specific wind data extraction come with their own uncertainties resulting from the effects of factors not captured by the reanalysis model resolution and the stationarity of relationships identified between the short-term and long-term datasets. Further, biases and uncertainties from the reanalysis model can carry through processes used to obtain local information and, as such, need to be accounted for in any analysis or application of the reanalyzed data.

Many studies have utilized reanalyzed wind fields without any critical assessment of their skill, accuracy, or uncertainty, often assuming them to be representative of observations or conducting only limited, qualitative checks on the results. Some have used reanalyzed wind fields to verify the output of climate models (Kumar et al. 2015; Schoof and Pryor 2014) or to assess the effects of teleconnections on regional wind energy potential (Kriesche and Schlosser 2014). Several studies have utilized reanalyzed wind data to model wind energy variability in Scandinavia (Olauson and Bergkvist 2015), Ireland (Kubik et al. 2013), Europe (Bett et al. 2013), China (Yu et al. 2016), the conterminous United States (Yu et al. 2015; Gunturu and Schlosser 2012; Pryor et al. 2012), and the greater Great Lakes region (Fisher et al. 2013; Li et al. 2010). Mizukami et al. (2016) linearly interpolated reanalyzed wind data as part of a suite of downscaled data for use in hydrological applications.

Work that has been done to quantify the skill of various reanalyzed wind datasets has found nonnegligible biases, particularly in hourly or subdaily variations, and in long-term regional trends. He et al. (2010) compared two early reanalyses against stations in North America using diurnal Weibull distribution parameters, finding larger biases in nighttime wind speeds and those associated with rougher or more complex terrain. Rose and Apt (2016) and Decker et al. (2012) compared reanalyzed wind speeds against data collected at meteorological and flux tower data, respectively, finding that root-mean-square error (RMSE) declined with longer time steps while correlations exhibited only minor improvements, though both incurred added uncertainties due to the necessary vertical extrapolation from $10 \mathrm{~m}$. Decker et al. (2012) further assessed daily and monthly average wind speeds, finding RMSE values of $2-5 \mathrm{~m} \mathrm{~s}^{-1}$ and correlations of $0.4-0.9$ at most tower locations for several reanalysis datasets. Several reanalysis datasets

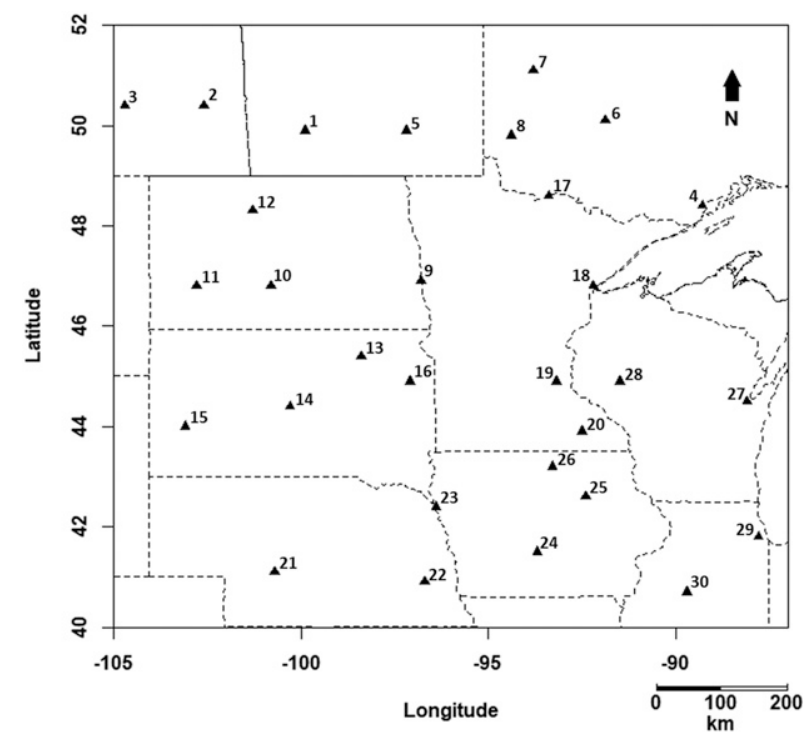

FIG. 1. Map of the upper Midwest with the locations of the observing stations denoted. The numbers correspond to those found in Table 2.

were compared to surface wind observations for Germany (Kaiser-Weiss et al. 2015) and in the Arctic (Lindsay et al. 2014), with both studies concluding that increased resolution and data assimilation in later generations of reanalysis model significantly improved wind representation in each region. Studies that have assessed longterm wind speeds in the reanalysis datasets have found insignificant or even positive trends, in contrast to the significant declines found in observations over the last several decades over land areas outside of the polar regions (McVicar et al. 2012). Trend discrepancies have been postulated to result from potential inhomogeneities in the observations, unresolved biases in the models, or possibly due to low-frequency teleconnection influences or regional radiative forcing patterns (Bichet et al. 2012; Pryor et al. 2009).

This study builds on that literature by assessing the skill of six widely used global reanalysis datasets in representing daily and monthly $10-\mathrm{m}$ wind speeds for the upper Midwest $\left(40^{\circ}-52^{\circ} \mathrm{N}, 87^{\circ}-105^{\circ} \mathrm{W}\right.$; see Fig. 1) over the period from January 1979 to December 2016. Many studies have focused on subdaily wind variability, though daily averaged wind speeds have been used in wind energy applications (Kirchner-Bossi et al. 2015). As such, in this work I focus primarily on daily average wind speeds but also include monthly average wind speeds to assess how low-frequency wind variability is represented in the reanalyses. There are a variety of methods used in the literature to assess the skill of the reanalyses, and as no one method is widely embraced, several are used in this work to quantify biases, 
distributions, and long-term trends. Section 2 of this paper details the reanalyses and the observational data used while section 3 describes the methods. Section 4 will discuss the results, and section 5 will conclude with a discussion of the ramifications of this work.

\section{Data}

\section{a. Reanalyses}

This study assesses the wind speed output from six reanalysis datasets: the National Centers for Environmental Prediction-U.S. Department of Energy (NCEP-DOE) Reanalysis-2 (R2), the National Oceanic and Atmospheric Administration-Cooperative Institute for Research in Environmental Sciences (NOAA-CIRES) Twentieth Century Reanalysis (20CR), the European Centre for Medium-Range Weather Forecasting (ECMWF) interim reanalysis (ERA-Interim), the Modern-Era Retrospective Analysis for Research and Applications version 2 (MERRA-2), the Japanese 55-year Reanalysis (JRA55), and the NCEP Climate Forecast System Reanalysis (CFSRv1 and CFSRv2; hereafter CFSR). General details and data sources for each of the reanalyses are provided in Table 1, with technical details provided in the listed documentation. The data were obtained in $U$ - and $V$-component format in either 1-hourly or 4-hourly time steps. Wind speed was calculated from the components at each time step and averaged to obtain daily wind speeds in meters per second. Maps of the average regional wind speeds over the period of interest are shown for each of the reanalyses in Fig. 2, with notable differences in the pattern of mean winds as expressed by the varying resolutions of the models.

Fujiwara et al. (2017) provides an in-depth analysis and comparison of several reanalysis datasets, including the ones utilized here. The atmospheric models that form the core of the reanalyses are similar to those used for weather forecasting and climate research, with most models run using prescribed sea surface temperatures, sea ice coverage, and land surface characteristics, though some of the newest model versions allow for limited interactions of coupled oceanic and sea ice components (Lindsay et al. 2014). Data assimilation varies between the reanalyses, with most utilizing the 3D-Var or 4D-Var schemes, though the Kalman ensemble (KE) filter was used in the 20CR iterations while MERRA-2 made use of a modified version of 3D-Var through incremental analysis updates (Compo et al. 2011; Dee et al. 2011; Kanamitsu et al. 2002). Each assimilation method attempts to correct model variables using collocated

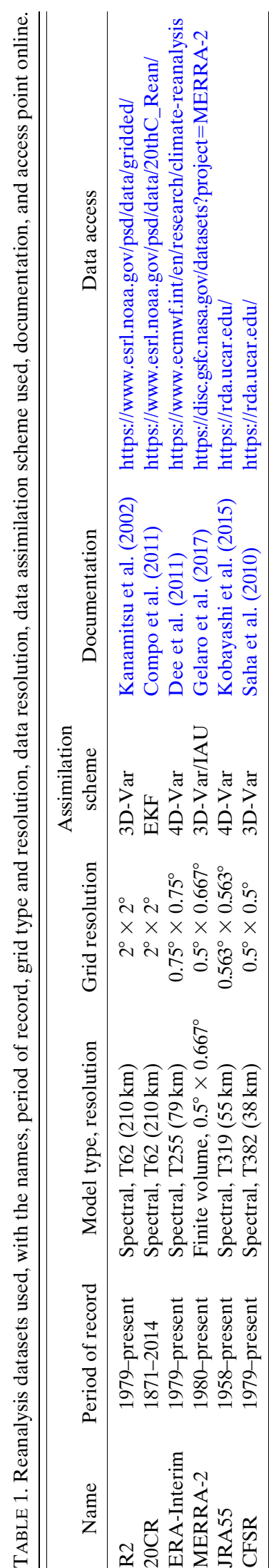




\section{Reanalyzed Wind Climatology Maps}
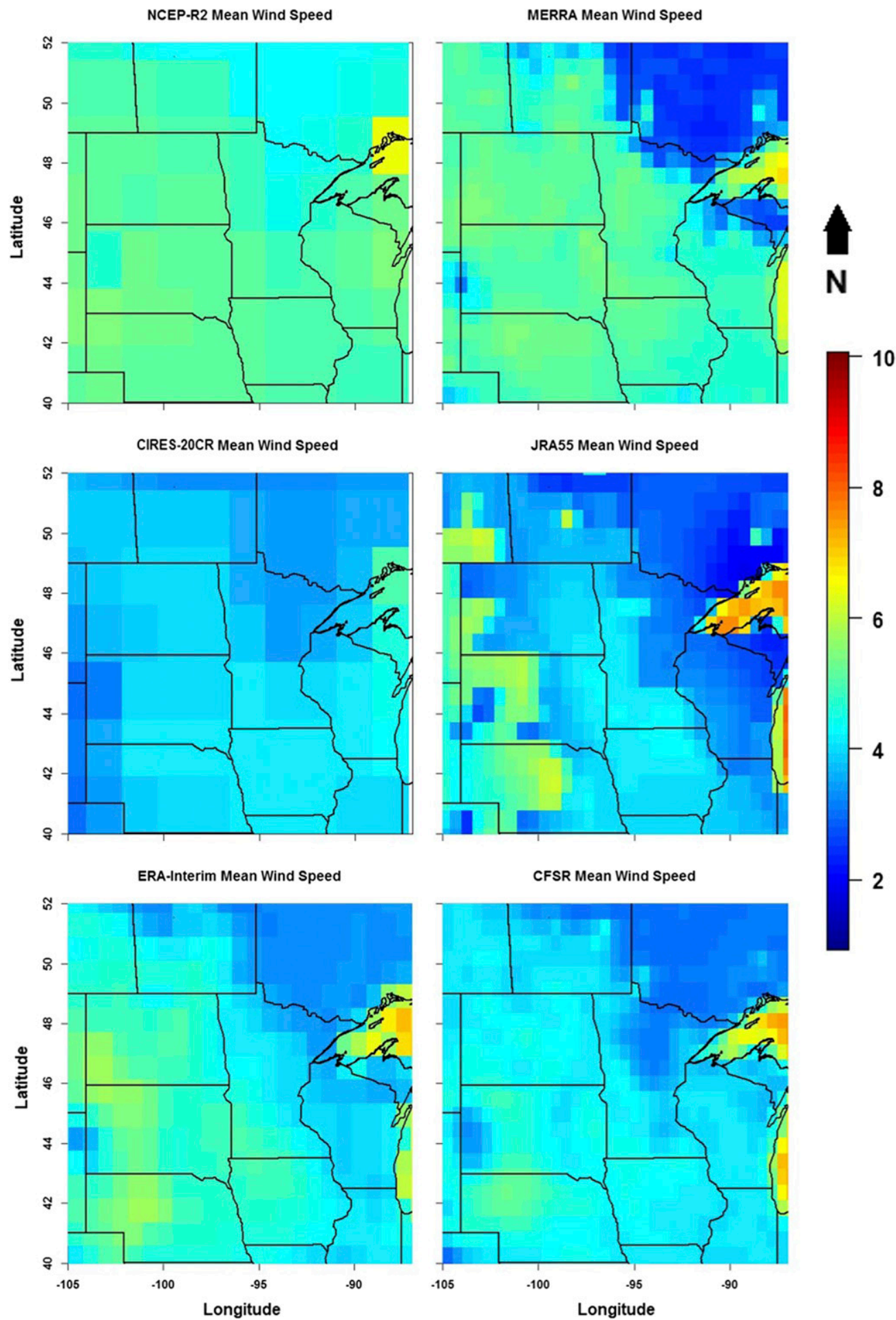

FIG. 2. Maps of the average 10-m wind speeds (AGL) over the 1979-2016 period for the upper Midwest. 
TABLE 2. Station locations, altitudes, average hours used to calculate daily mean wind speeds, and the period of record. Numbers in the first column correspond to those in Fig. 1.

\begin{tabular}{|c|c|c|c|c|c|c|}
\hline Number & Location & Lat $\left(^{\circ}\right)$ & Lon $\left({ }^{\circ}\right)$ & Alt (m) & Avg hours & Period of record \\
\hline 1 & Brandon, MB & 49.9 & -99.9 & 409.3 & 23.6 & 1979-2016 \\
\hline 2 & Broadview, SK & 50.4 & -102.6 & 600 & 23.4 & 1979-2016 \\
\hline 3 & Regina, SK & 50.4 & -104.7 & 577.3 & 23.6 & 1979-2016, no 1992 \\
\hline 4 & Thunder Bay, ON & 48.4 & -89.3 & 199 & 23.5 & 1979-2016 \\
\hline 5 & Winnipeg, MB & 49.9 & -97.2 & 238.7 & 23.8 & 1982-2016 \\
\hline 6 & Sioux Lookout, ON & 50.1 & -91.9 & 383.4 & 23.5 & 1982-2016 \\
\hline 7 & Redlake, ON & 51.1 & -93.8 & 385.6 & 16.7 & 1982-2016 \\
\hline 8 & Kenora, ON & 49.8 & -94.4 & 406 & 23.5 & 1982-2016 \\
\hline 9 & Fargo, ND & 46.9 & -96.8 & 274.3 & 24.0 & 1979-2016 \\
\hline 10 & Bismarck, ND & 46.8 & -100.8 & 503.2 & 24.0 & 1979-2016 \\
\hline 11 & Dickinson, ND & 46.8 & -102.8 & 787.3 & 23.2 & 1979-July 2010 \\
\hline 12 & Minot, ND & 48.3 & -101.3 & 507.5 & 23.4 & 1979-2016 \\
\hline 13 & Aberdeen, SD & 45.4 & -98.4 & 395.3 & 22.4 & 1979-2016 \\
\hline 14 & Pierre, SD & 44.4 & -100.3 & 526.1 & 23.5 & 1979-July 2010 \\
\hline 15 & Rapid City, SD & 44 & -103.1 & 963.2 & 23.4 & 1979-2016 \\
\hline 16 & Watertown, SD & 44.9 & -97.1 & 532.8 & 23.0 & 1979-2016 \\
\hline 17 & Int. Falls, MN & 48.6 & -93.4 & 360.6 & 23.0 & 1979-2016 \\
\hline 18 & Duluth, MN & 46.8 & -92.2 & 436.8 & 24.0 & 1979-2016 \\
\hline 19 & Minneapolis, MN & 44.9 & -93.2 & 265.8 & 24.0 & 1979-2016 \\
\hline 20 & Rochester, MN & 43.9 & -92.5 & 397.5 & 23.3 & 1979-2016 \\
\hline 21 & North Platte, NE & 41.1 & -100.7 & 846.7 & 24.0 & 1979-2016 \\
\hline 22 & Lincoln, NE & 40.9 & -96.7 & 362.7 & 23.9 & 1979-2016 \\
\hline 23 & Sioux City, IA & 42.4 & -96.4 & 333.8 & 24.0 & 1979-2016 \\
\hline 24 & Des Moines, IA & 41.5 & -93.7 & 291.7 & 24.0 & 1979-2016 \\
\hline 25 & Waterloo, IA & 42.6 & -92.4 & 264.6 & 24.0 & 1979-2016 \\
\hline 26 & Mason City, IA & 43.2 & -93.3 & 373.4 & 23.9 & 1979-2016 \\
\hline 27 & Green Bay, WI & 44.5 & -88.1 & 209.4 & 24.0 & 1979-2016 \\
\hline 28 & Eau Claire, WI & 44.9 & -91.5 & 269.8 & 23.9 & 1979-2016 \\
\hline 29 & Chicago, IL & 41.8 & -87.8 & 186.5 & 23.0 & 1979-2016 \\
\hline 30 & Peoria, IL & 40.7 & -89.7 & 198.1 & 24.0 & 1979-2016 \\
\hline
\end{tabular}

observations, with studies having found that problems in the assimilated data streams adversely affect model skill (Krueger et al. 2013; Smits et al. 2005). For this work, it is notable that surface $(10 \mathrm{~m})$ winds are calculated in the reanalyses by interpolating to the topographical geopotential level through a boundary layer scheme, with only later-generation models interpolating to heights above and below $10 \mathrm{~m}$ above ground level (AGL) for use in hydrological and wind energy applications. Global reanalyses do not assimilate land surface station wind data, allowing wind speed observations to act as an independent variable for model verification (Rienecker et al. 2011; Saha et al. 2010; Kanamitsu et al. 2002). The North American Regional Reanalysis (NARR) did assimilate wind data at a relatively high resolution but was not considered here in order to maintain consistency in comparing global reanalysis output against independent observations.

\section{b. In situ observations}

Daily wind speed observations were retrieved from the Global Surface Summary of the Day (https://www.ncdc. noaa.gov/isd/products) dataset, which was derived from the
Integrated Surface Hourly (ISH) land station dataset. The ISH was collated from multiple sources and reported by the National Centers for Environmental Information (NCEI) and Federal Climate Complex (Lott and Baldwin 2002) in units of knots, which were converted to meters per second for this analysis. Most of the wind data were collected by cup anemometers with a standard accuracy of about $1 \mathrm{~m} \mathrm{~s}^{-1}$ (Nadolski 1998), though a shift to sonic anemometers with a standard accuracy of about $0.1 \mathrm{~m} \mathrm{~s}^{-1}$ (Högström and Smedman 2004) occurred at most locations between 2003 and 2008. Thirty stations were selected from within the study area (see Table 2) that contained the most complete data for the desired period (1979-2016). All the station records had missing data, with six stations missing a few years either at the beginning of the period of interest or at the end. The station data were subjected to over 57 quality-control checks while in preparation for the ISH, mostly to correct for weather condition inconsistencies and unexplained spikes, as well as to bring the measurements in line with the general best practices outlined by the World Meteorological Organization (Smith et al. 2011; Lott 2004). Further quality controls were applied in this analysis by 

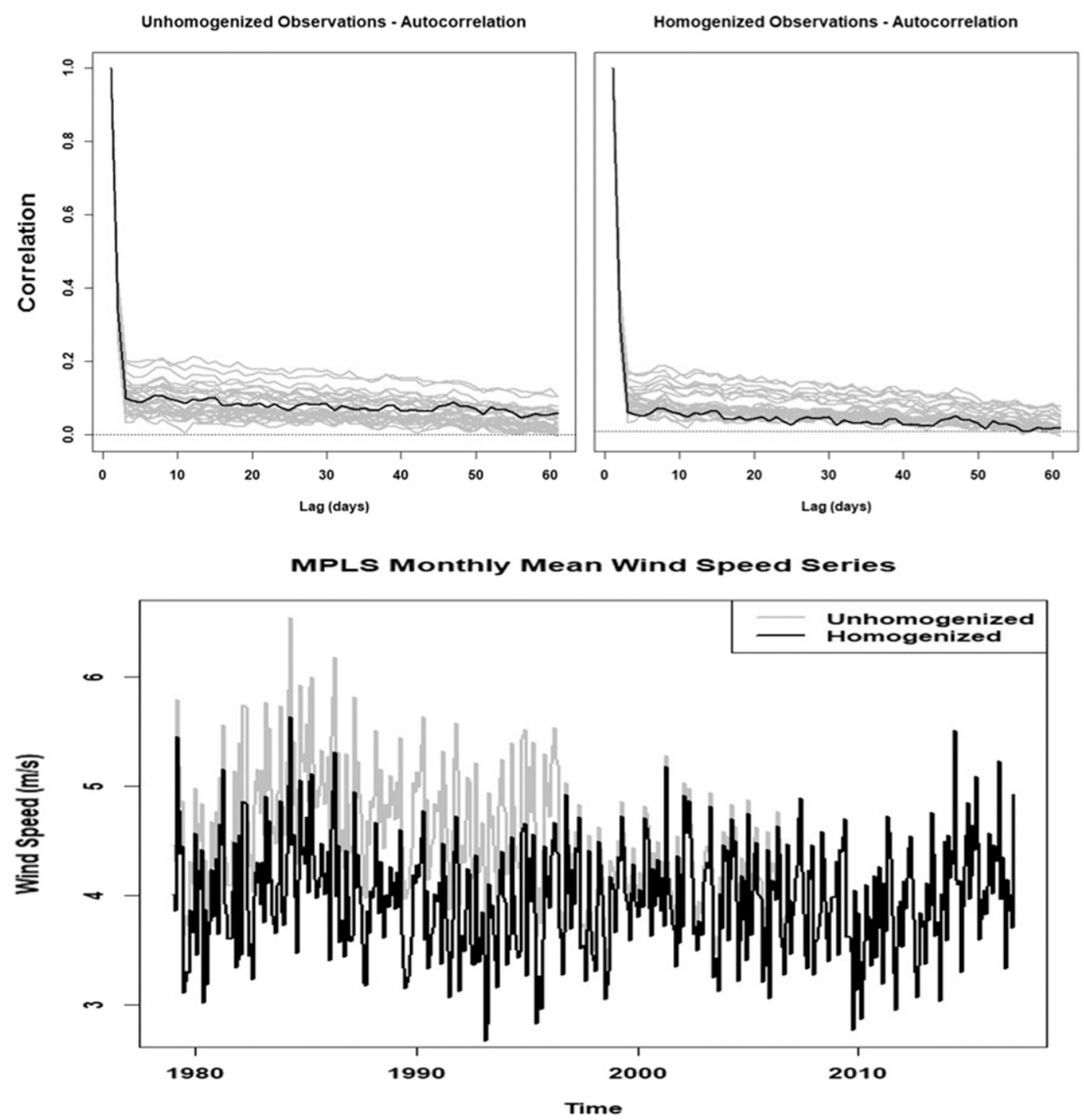

FIG. 3. (top) Autocorrelation plots for the (left) unhomogenized and (right) homogenized data. The black line corresponds to the data from Minneapolis-St. Paul International Airport (MPLS) station (19 in Table 2 and Fig. 1). (bottom) Time series from the MPLS station, showing the unhomogenized (gray) and homogenized (black) data. Note the jumps in the gray data in the late 1990s and the mid-2000s.

removing daily average wind speeds derived from fewer than $12 \mathrm{~h}$ of measurements. The resulting time series contained between $85 \%$ and $97 \%$ of the possible 13880 daily observations at each station. These quality controls did not account for long-term inhomogeneities due to station location shifts, instrument changes, or changes to the local environment, which are handled in the next section.

\section{Methods}

\section{a. Homogenization}

Inhomogeneities are common in records of many climate variables, including wind speed. These result from modifications in station location, instrumentation, or reporting practices, as well as local environmental changes such as land-use conversions and the buildup of infrastructure. Studies often note these biases when assessing station wind climatologies and trends, though attempts to remove them are often limited by a lack of supporting metadata or independently verified reference records with which to correct the time series (Azorin-Molina et al. 2014; Kubik et al. 2013; Wan et al. 2010; Klink 2002). One characteristic of inhomogeneous time series is the abnormally high persistence as measured by the autocorrelation function (ACF), which should tend toward zero at larger lag times but which maintains a significant level of long-range dependence 
(Rust et al. 2008). This is true of the observations used here, where many of the unhomogenized wind speed time series from the region exhibit autocorrelation values as high as 0.2 at 20 days and 0.1 at 60 days (see Fig. 3). Homogenization has been shown to reduce this dependence in station wind series (Kirchmeier et al. 2014; Rust et al. 2008).

Kirchmeier et al. (2014) made use of a quantile mapping method in which metadata for stations in the greater Great Lakes region were used to find the longest period of data in which the station location was the same and correct the remaining portion of each station record to fit the cumulative distribution function (CDF) of the data within that period. A similar approach is applied here through the fitQmapQUANT and doQmapQUANT functions (Gudmundsson 2016) in the statistical package R (R Core Team 2017). Metadata for the U.S. stations (https://www.ncdc.noaa.gov/IPS/lcd/lcd.html) showed that over the period 1979-2016, there was a significant station move and/or a change in anemometer height (to $10 \mathrm{~m} \mathrm{AGL)} \mathrm{for} \mathrm{all} \mathrm{stations} \mathrm{in} \mathrm{the} \mathrm{1990s} \mathrm{due} \mathrm{to} \mathrm{the}$ Automated Surface Observing System (ASOS) standardization. This resulted in a small negative bias in wind speeds (Lott 2004). Three stations experienced anemometer height changes before the ASOS standardization while four stations were changed to $8-\mathrm{m}$ measurements for ASOS due to local restrictions. There was also a shift from the use of cup to sonic anemometers in the $2000 \mathrm{~s}$, which could result in a negative bias of $6 \%-16 \%$ due to cup anemometer overspeeding (Wieringa 1980; Izumi and Barad 1970).

Each wind speed observation series was homogenized by partitioning the series based on the changes noted in the metadata, with breaks at the anemometer height changes, the ASOS standardization, and the shift to the sonic anemometers. The last section of data, being measured in a single location by the sonic anemometer, was taken to be the most accurate and was used to construct a CDF separated into 200 quantiles. The middle section, after the ASOS implementation but at the same location, was quantile corrected by constructing a CDF from its values and obtaining a correction factor by calculating the difference between the CDFs, with values not found in the quantiles estimated through linear interpolation. Each data point in the middle section was then corrected by adding the appropriate adjustment factor. To correct the remaining sections, a new CDF was constructed from the now-corrected time series made up of the corrected middle and last sections. Offsets for the first section were then calculated and added to the data just as for the middle section. Finally, the four stations where the ASOS anemometer heights were restrained to $8 \mathrm{~m}$ AGL were corrected to $10 \mathrm{~m}$ via the $1 / 7$ power rule. The Canadian station metadata were unavailable, though by comparing the station data to the output from Wan et al. (2010), it was found that the lattermost portions of each station series matched the previously homogenized data. The same quantile correction was applied as in the U.S. stations, with the data from the period over which the datasets matched being used to correct the remainder of the time series. As seen in Fig. 3, the autocorrelation was reduced and thus exhibited less long-term persistence. Further justification is found in the consistency of the negative biases found due to the ASOS station moves and the $6 \%$ decline in the corrected wind speeds after accounting for the shift to sonic anemometers, consistent with the biases found in Lott (2004) and Wieringa (1980), respectively.

\section{b. Model-station colocation and spatiotemporal comparison}

In situ observations were compared to the data from the reanalysis grid cells that contained each station location using the nearest neighbor approach. While the direct comparison of site-specific data to spatially averaged data from a grid cell carries inherent uncertainty, higher-resolution models have been compared to observations in this manner to avoid the added uncertainties associated with interpolation (Sharp et al. 2015), and the comparison is performed here for all reanalysis models-regardless of resolution-for the sake of consistency. One instance of two stations being encapsulated by the same grid square occurred in R2 and $20 \mathrm{CR}$, though the results exhibited no significant differences when they were averaged in the statistics versus when they were not. Going forward, the reanalysis grid square subset used to compare to the observations will be referred to as the station grid squares (SGSs). Daily mean wind speeds were averaged to obtain monthly time series for both the observations and the reanalyses, and both the daily and monthly time series were subset into spring (MAM), summer (JJA), autumn (SON), and winter (DJF) so as to make seasonal comparisons. Statistical measures of skill, Weibull parameters, and trends are calculated for each SGS and averaged to obtain the mean regional comparison, though variations within the region and between time intervals within the period of interest are also discussed.

\section{c. Statistical comparison}

The SGSs were compared to the observations using commonly applied statistical metrics in wind assessments, specifically the Weibull parameters, the Pearson correlations, the mean differences (MD), the mean 
absolute error (MAE), the RMSE, and the linear trends. The metrics were calculated for each station-SGS pair and averaged to obtain regional values discussed in the results. The MD values indicate the sign of the wind speed biases, while the magnitudes are captured by the MAE and RMSE. Trends $\left(\mathrm{m} \mathrm{s}^{-1}\right.$ decade $\left.^{-1}\right)$ and the associated 0.95 confidence intervals were calculated from the daily data using least squares regression for each station and SGS. The Weibull distribution is commonly used to represent wind speeds. While the distribution has been shown to be less skillful in representing nocturnal wind regimes and wind distributions over complex terrain (Bett et al. 2013; He et al. 2010), these concerns are somewhat ameliorated through the focus on the upper Midwest and the use of daily mean and monthly mean wind speeds for the analysis. The Weibull probability density function is defined as

$$
P(U)=\frac{k}{\gamma}\left(\frac{U}{\gamma}\right)^{k} \exp \left[-\left(\frac{U}{\gamma}\right)^{k}\right],
$$

where $U$ is the wind speed, $k$ is the shape parameter (pointedness, dimensionless), and $\gamma$ is the scale parameter (central tendency; $\mathrm{m} \mathrm{s}^{-1}$ ). The shape and scale parameters were estimated by the fitdist function in R (Delignette-Muller and Dutang 2015), using maximum likelihood fitting, for each station and SGS time series, from which the regionally averaged distribution parameters were calculated.

\section{Results}

\section{a. Skill scores}

Table 3 shows the MD, MAE, and RMSE values, as well as the correlations, calculated from the observed and reanalyzed daily data from the full period of record, as well as the seasonal subsets of daily values. Daily MD values ranged from -0.464 to $0.703 \mathrm{~m} \mathrm{~s}^{-1}$, and as expected, were smaller in magnitude than the MAE and RMSE. Daily RMSE values $\left(1.032-1.946 \mathrm{~m} \mathrm{~s}^{-1}\right)$ were larger than the daily MAE $\left(0.807-1.523 \mathrm{~m} \mathrm{~s}^{-1}\right)$ but were in agreement on the relative skill of the reanalyses. The reanalyzed winds exhibited fairly high correlation with daily mean observations, with lower-resolution models (R2 and 20CR) having lower correlations of $0.71-0.75$ and higher-resolution models having correlations ranging from 0.85 to 0.89 . R2 had the largest MAE and RMSE values, followed by 20CR and JRA55, MERRA-2, ERA-Interim, and CFSR, which had the smallest daily biases. The scores generally improved with increased resolution and complexity, though the pattern was less apparent when only the higher-resolution reanalyses
TABLE 3. Daily measures of skill $\left(\mathrm{m} \mathrm{s}^{-1}\right)$ and correlations (COR) for each reanalysis averaged from all station-SGS pairs. Reanalyses are listed in order of increasing resolution, as in Table 1 . The top section is for the full period of record, followed by spring, summer, autumn, and winter days. Boldface MAE and RMSE values are the lowest in each section. Boldface correlations are the highest in each section.

\begin{tabular}{lrlll}
\hline \hline & MD & MAE & RMSE & COR \\
\hline Full period of record & & & & \\
R2 & 0.703 & 1.523 & 1.946 & 0.75 \\
20CR & -0.317 & 1.295 & 1.661 & 0.71 \\
ERA-Interim & 0.127 & 0.869 & 1.111 & 0.85 \\
MERRA-2 & 0.415 & 0.877 & 1.088 & $\mathbf{0 . 8 9}$ \\
JRA55 & -0.464 & 0.976 & 1.212 & 0.88 \\
CFSR & -0.209 & $\mathbf{0 . 8 0 7}$ & $\mathbf{1 . 0 3 2}$ & 0.88 \\
Spring subset & & & & \\
R2 & 0.483 & 1.48 & 1.89 & 0.77 \\
20CR & -0.537 & 1.401 & 1.799 & 0.68 \\
ERA-Interim & -0.154 & 0.873 & 1.113 & 0.86 \\
MERRA-2 & 0.344 & $\mathbf{0 . 8 5 2}$ & $\mathbf{1 . 0 6 8}$ & $\mathbf{0 . 9 0}$ \\
JRA55 & -0.492 & 1.011 & 1.256 & 0.88 \\
CFSR & -0.529 & 0.876 & 1.103 & $\mathbf{0 . 9 0}$ \\
Summer subset & & & & \\
R2 & 0.315 & 1.225 & 1.554 & 0.73 \\
20CR & -0.517 & 1.191 & 1.513 & 0.63 \\
ERA-Interim & 0.135 & 0.753 & 0.949 & 0.83 \\
MERRA-2 & 0.297 & 0.744 & 0.921 & $\mathbf{0 . 8 7}$ \\
JRA55 & -0.514 & 0.905 & 1.11 & 0.83 \\
CFSR & -0.366 & $\mathbf{0 . 7 1 4}$ & $\mathbf{0 . 8 9 5}$ & $\mathbf{0 . 8 7}$ \\
Autumn subset & & & & \\
R2 & 0.884 & 1.56 & 1.969 & 0.77 \\
20CR & -0.169 & 1.236 & 1.581 & 0.74 \\
ERA-Interim & 0.16 & 0.828 & 1.044 & 0.88 \\
MERRA-2 & 0.459 & 0.9 & 1.09 & $\mathbf{0 . 9 1}$ \\
JRA55 & -0.457 & 0.982 & 1.216 & 0.89 \\
CFSR & -0.094 & $\mathbf{0 . 7 5 8}$ & $\mathbf{0 . 9 6 3}$ & 0.90 \\
Winter subset & & & & \\
R2 & 1.139 & 1.832 & 2.288 & 0.73 \\
20CR & -0.036 & 1.352 & 1.717 & 0.72 \\
ERA-Interim & 0.374 & 1.025 & 1.284 & 0.84 \\
MERRA-2 & 0.563 & 1.014 & 1.232 & $\mathbf{0 . 8 9}$ \\
JRA55 & -0.392 & 1.006 & 1.244 & $\mathbf{0 . 8 9}$ \\
CFSR & 0.161 & $\mathbf{0 . 8 8}$ & $\mathbf{1 . 1 0 7}$ & $\mathbf{0 . 8 9}$ \\
\hline & & & & \\
\hline
\end{tabular}

were considered (ERA-Interim, MERRA-2, JRA55, CFSR), consistent with previous work on reanalyzed Arctic winds (Lindsay et al. 2014) and winds within the boundary layer in the Midwest (Decker et al. 2012). The difference of RMSE and MAE scores, which indicates the relative presence of larger errors, is largest for R2 and smallest for MERRA-2. MD values indicate that overall, daily biases are positive (reanalysis wind speeds are faster than observed wind speeds) for R2, ERAInterim, and MERRA-2, while 20CR, JRA55, and CFSR exhibit negative biases (slower than observed wind speeds). Lindsay et al. (2014) also found that R2 and 


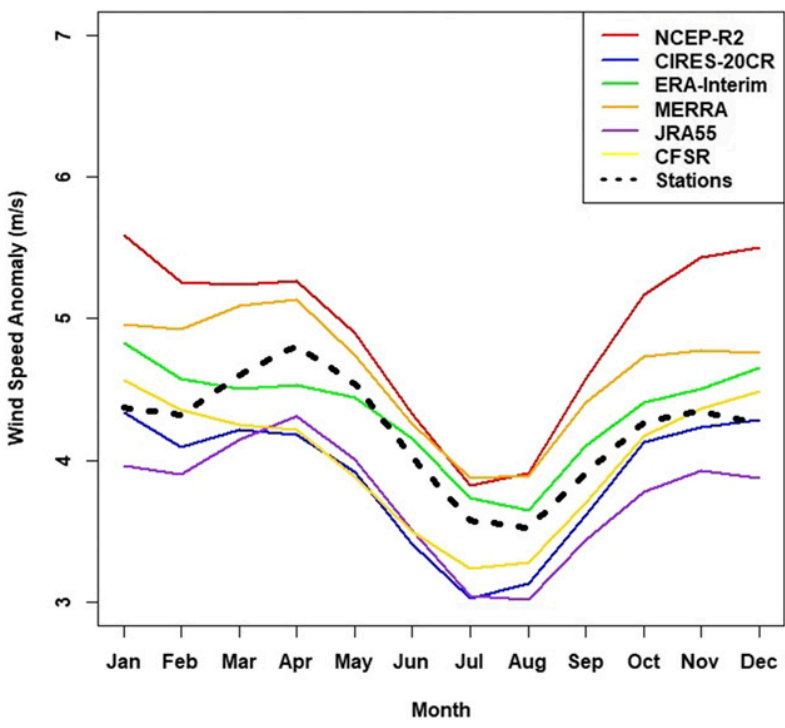

FIG. 4. Annual wind speed by month $\left(\mathrm{m} \mathrm{s}^{-1}\right)$. Black dashed line shows the observations.

CFSR exhibited positive and negative biases, respectively; however MERRA-2 was found to produce slower than observed winds in the Arctic. Rose and Apt (2016) also found a negative bias in wind speeds from CFSR.

Scores computed from daily data exhibit important seasonal variations. The observed seasonal wind pattern (Fig. 4) exhibits the strongest winds in April $\left(5.0 \mathrm{~m} \mathrm{~s}^{-1}\right)$ and the weakest in August $\left(3.5 \mathrm{~m} \mathrm{~s}^{-1}\right)$. In contrast, reanalyses tend to produce peaks in the winter months and lulls in the late summer months, though JRA55 and MERRA-2 better captured the observed April peak. As was the case for the values calculated from the daily means, monthly MAE and RMSE strongly covaried and were smallest for each reanalysis in the summer and largest in winter or spring. Daily seasonal correlations varied by less than 0.1 for each reanalysis, with slightly lower correlations in summer and winter compared to autumn and spring. This pattern is consistent with previous work on wind speeds in the upper Midwest, which noted slower winds in the summer due to the northward displacement of the jet stream and the presence of relatively high pressure, as well as the higher velocities and variability in the other seasons from higher-frequency cyclone activity (Klink 2007, 1999). CFSR tended to obtain the lowest errors overall, though spring errors were lowest for MERRA-2. MERRA-2 also obtained the highest correlations in each season, though the correlations for CFSR and JRA55 were comparable. Figure 4 also gives a sense of the seasonal MD values, which were consistently positive throughout all seasons for R2 and MERRA-2 and were consistently negative for 20CR and JRA55. Spring wind speeds were slower than observed in
TABLE 4. As in Table 3, but for the monthly wind speed series comparisons.

\begin{tabular}{lclll}
\hline \hline & MD & MAE & RMSE & COR \\
\hline Full period of record & & & & \\
R2 & 0.703 & 0.848 & 0.981 & 0.70 \\
20CR & -0.317 & 0.697 & 0.81 & 0.67 \\
ERA-Interim & 0.127 & $\mathbf{0 . 5 4 4}$ & $\mathbf{0 . 6 5 4}$ & 0.74 \\
MERRA-2 & 0.416 & 0.637 & 0.721 & $\mathbf{0 . 8 1}$ \\
JRA55 & -0.463 & 0.793 & 0.875 & 0.76 \\
CFSR & -0.208 & 0.582 & 0.685 & 0.73 \\
Spring subset & & & & \\
R2 & 0.483 & 0.701 & 0.801 & 0.67 \\
20CR & -0.538 & 0.775 & 0.88 & 0.54 \\
ERA-Interim & -0.155 & $\mathbf{0 . 5 2}$ & $\mathbf{0 . 6}$ & 0.72 \\
MERRA-2 & 0.345 & 0.602 & 0.675 & $\mathbf{0 . 7 6}$ \\
JRA55 & -0.49 & 0.815 & 0.888 & 0.67 \\
CFSR & -0.528 & 0.678 & 0.752 & 0.72 \\
Summer subset & & & & \\
R2 & 0.315 & 0.553 & 0.634 & 0.70 \\
20CR & -0.519 & 0.687 & 0.777 & 0.56 \\
ERA-Interim & 0.134 & $\mathbf{0 . 4 3 3}$ & $\mathbf{0 . 5}$ & $\mathbf{0 . 7 6}$ \\
MERRA-2 & 0.296 & 0.516 & 0.581 & 0.75 \\
JRA55 & -0.514 & 0.727 & 0.798 & 0.65 \\
CFSR & -0.369 & 0.525 & 0.59 & 0.72 \\
Autumn subset & & & & \\
R2 & 0.883 & 0.957 & 1.049 & 0.71 \\
20CR & -0.17 & 0.637 & 0.726 & 0.68 \\
ERA-Interim & 0.16 & 0.521 & 0.593 & 0.78 \\
MERRA-2 & 0.458 & 0.679 & 0.741 & $\mathbf{0 . 7 9}$ \\
JRA55 & -0.457 & 0.813 & 0.885 & 0.70 \\
CFSR & -0.094 & $\mathbf{0 . 5 1 7}$ & $\mathbf{0 . 5 8 9}$ & 0.77 \\
Winter subset & & & & \\
R2 & 1.132 & 1.182 & 1.281 & 0.66 \\
20CR & -0.041 & 0.686 & 0.78 & 0.65 \\
ERA-Interim & 0.37 & 0.702 & 0.797 & 0.70 \\
MERRA-2 & 0.565 & 0.75 & 0.822 & $\mathbf{0 . 7 7}$ \\
JRA55 & -0.391 & 0.817 & 0.89 & 0.71 \\
CFSR & 0.158 & $\mathbf{0 . 6 0 8}$ & $\mathbf{0 . 6 8 6}$ & 0.75 \\
\hline
\end{tabular}

ERA-Interim while summer, autumn, and winter winds were faster. CFSR winds were slower than observed in every season except winter.

The MD, MAE, RMSE, and correlation values for the observed and reanalyzed monthly mean winds, as well as their seasonal subsets, are displayed in Table 4. MD values were the same as those of the daily data to within $0.1 \mathrm{~m} \mathrm{~s}^{-1}$ while MAE $\left(0.544-0.848 \mathrm{~m} \mathrm{~s}^{-1}\right)$ and RMSE $\left(0.654-0.981 \mathrm{~m} \mathrm{~s}^{-1}\right)$ values were smaller than the daily values by $17 \%-55 \%$ and $27 \%-59 \%$, respectively. JRA55 exhibited the smallest differences between the daily and monthly MAE and RMSE scores while the largest differences occurred in the lower-resolution reanalyses. ERA-Interim exhibited the smallest overall monthly MAE and RMSE values, which manifested most clearly in the spring and summer series, while CFSR obtained the smallest monthly errors in autumn and 

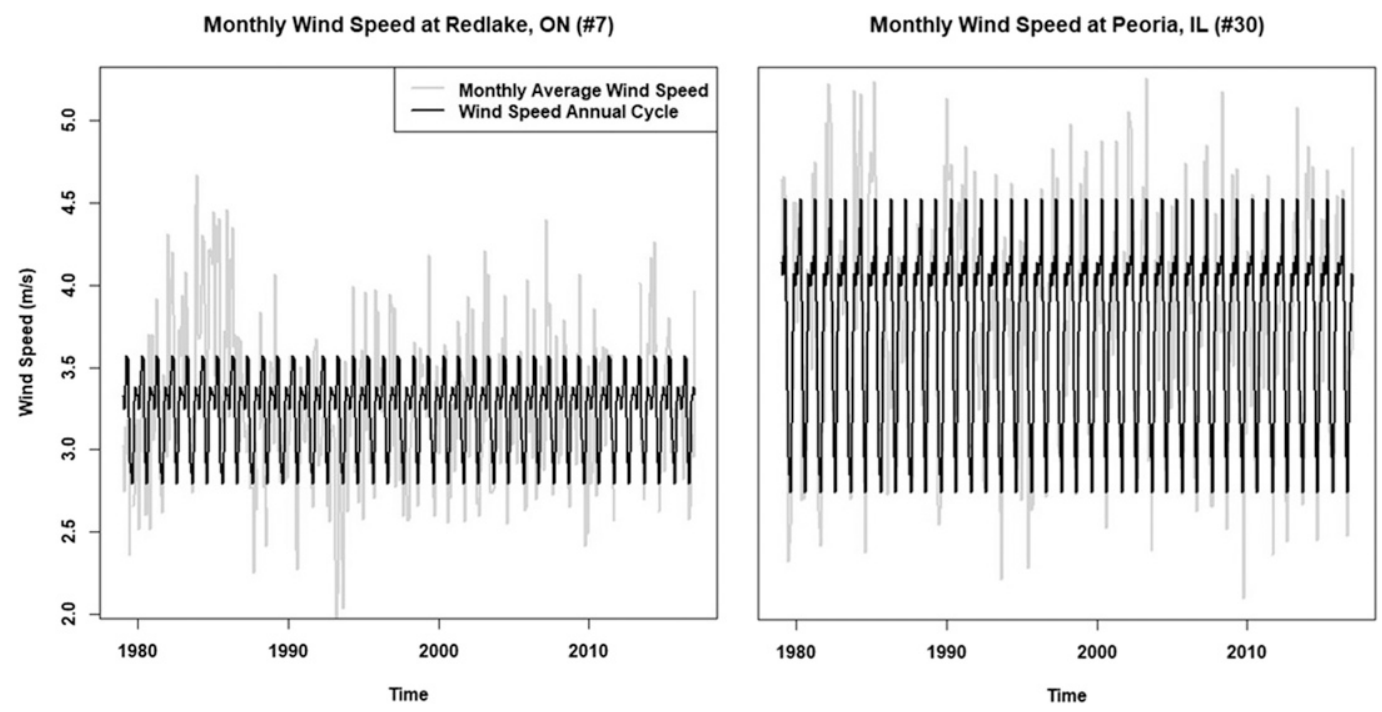

FIG. 5. Monthly wind speed (gray) and the mean monthly wind speed cycle (black) for the (left) Redlake, Ontario, and (right) Peoria, Illinois, stations. Note the large variations in Redlake monthly winds relative to the monthly cycle compared to those at Peoria.

winter. Seasonal, monthly correlations were more variable and smaller in magnitude than the corresponding daily values for each reanalysis and season. MERRA-2 produced the strongest correlations, though ERAInterim obtained the highest correlation for the summer months. Smaller correlations for monthly winds compared to daily winds have been noted in previous work (Toledo et al. 2015; Decker et al. 2012), though not all regions incur lower monthly correlations (Kaiser-Weiss et al. 2015). This could be due to the high variability of monthly wind speeds compared to the underlying annual cycles, shown here in Fig. 5 for the locations that consistently had largest and smallest monthly to daily correlation differences in the reanalysis comparisons. High monthly wind variability at Redlake is largely unconstrained by the annual wind cycle, while the monthly wind deviations from the annual cycle are smaller at Peoria and result in a monthly correlation that is greater than the daily value. High wind variability, including from longer averaging intervals, may result from the influence of local topography or land cover variations that remain unresolved at the resolutions of the reanalyses (Kaiser-Weiss et al. 2015).

\section{b. Distributions}

The parameters of the Weibull distributions are given for the daily and monthly observations and reanalyzed wind series in Table 5 and shown in Fig. 6. Daily wind speed shape and scale parameters for the observed station series were 2.46 and $4.75 \mathrm{~m} \mathrm{~s}^{-1}$, with reanalyzed ranges of $1.96-2.84$ and $4.22-5.54 \mathrm{~m} \mathrm{~s}^{-1}$, respectively. Monthly values for the observed winds were 7.28 and $4.49 \mathrm{~m} \mathrm{~s}^{-1}$, with reanalyzed ranges of $6.69-8.78$ and $4.01-5.26 \mathrm{~m} \mathrm{~s}^{-1}$, respectively. As expected, the monthly wind speeds exhibit larger shape parameters, indicating a tighter clustering of wind speeds about the central tendency. The larger spread of daily wind speeds result in scale values that are $0.05-0.4 \mathrm{~m} \mathrm{~s}^{-1}$ higher than the monthly values. Seasonal values of the daily and monthly parameters exhibited similar patterns. Scale parameters were consistently smallest in the summer, corresponding to slower winds during the warm season. The observed peak in the scale parameter occurred in spring; however, it varied between winter and spring in the reanalyses. Seasonal shape parameters computed for daily data from the reanalyses exhibited less variation than the seasonal shape parameters calculated from the monthly data.

R2 and 20CR consistently underestimated the shape parameters in all daily wind series and in all monthly wind series except in the winter. Shape parameter differences were positive but smaller in magnitude for all of the remaining reanalyses except JRA55, which exhibited negative shape values for the daily summer winds and for all monthly wind subsets. This would indicate that R2, 20CR, and, to an extent, JRA55 wind speeds exhibit a larger spread than the observations, while the rest of the reanalyzed winds are more tightly constrained about the central tendencies. Daily and monthly scale parameter values were similar in magnitude and sign to the mean differences reported in Tables 3 and 4. The combination of larger-than-observed shape and scale 
TABLE 5. Daily and monthly Weibull parameters [shape and scale $\left(\mathrm{m} \mathrm{s}^{-1}\right)$ ] estimated via R function fitdist (see text) for data all stations and SGSs. Boldface values are the reanalyzed parameters that were closest in each section.

\begin{tabular}{|c|c|c|c|c|c|c|c|c|c|c|}
\hline & \multicolumn{2}{|c|}{$\begin{array}{l}\text { Full period of } \\
\text { record }\end{array}$} & \multicolumn{2}{|c|}{ Spring subset } & \multicolumn{2}{|c|}{ Summer subset } & \multicolumn{2}{|c|}{ Autumn subset } & \multicolumn{2}{|c|}{ Winter subset } \\
\hline & Shape & Scale & Shape & Scale & Shape & Scale & Shape & Scale & Shape & Scale \\
\hline \multicolumn{11}{|l|}{ Daily } \\
\hline Stations & 2.461 & 4.753 & 2.604 & 5.239 & 2.734 & 4.168 & 2.435 & 4.712 & 2.424 & 4.867 \\
\hline $\mathrm{R} 2$ & 1.964 & 5.543 & 2.000 & 5.788 & 2.009 & 4.536 & 2.018 & 5.710 & 2.078 & 6.153 \\
\hline 20CR & 1.967 & 4.378 & 2.048 & 4.631 & 2.037 & 3.598 & 1.999 & 4.506 & 2.044 & 4.792 \\
\hline ERA-Interim & 2.726 & 4.882 & 2.824 & 5.049 & 2.812 & 4.315 & 2.710 & 4.883 & 2.862 & 5.265 \\
\hline MERRA-2 & 2.842 & 5.196 & 2.895 & 5.598 & 3.064 & 4.481 & 2.904 & 5.202 & 2.985 & 5.467 \\
\hline JRA55 & 2.533 & 4.221 & 2.707 & 4.670 & 2.689 & 3.587 & 2.550 & 4.189 & 2.611 & 4.413 \\
\hline CFSR & 2.779 & 4.497 & 2.894 & 4.622 & 3.075 & 3.734 & 2.853 & 4.581 & 2.961 & 5.012 \\
\hline \multicolumn{11}{|l|}{ Monthly } \\
\hline Stations & 7.276 & 4.485 & 9.721 & 4.879 & 8.580 & 3.914 & 8.847 & 4.402 & 8.568 & 4.551 \\
\hline $\mathrm{R} 2$ & 6.803 & 5.261 & 9.284 & 5.396 & 8.458 & 4.244 & 8.509 & 5.344 & 9.017 & 5.738 \\
\hline 20CR & 6.782 & 4.157 & 9.041 & 4.322 & 8.206 & 3.373 & 8.592 & 4.220 & 9.108 & 4.461 \\
\hline ERA-Interim & 8.591 & 4.590 & 11.453 & 4.682 & 10.199 & 4.027 & 10.998 & 4.532 & 10.185 & 4.915 \\
\hline MERRA-2 & 8.780 & 4.893 & 11.868 & 5.198 & 11.575 & 4.177 & 12.173 & 4.833 & 10.852 & 5.099 \\
\hline JRA55 & 6.685 & 4.005 & 9.664 & 4.359 & 7.453 & 3.387 & 8.054 & 3.932 & 8.482 & 4.129 \\
\hline CFSR & 7.959 & 4.257 & 11.307 & 4.300 & 11.883 & 3.475 & 10.472 & 4.280 & 11.197 & 4.665 \\
\hline
\end{tabular}

values in $\mathrm{R} 2$ resulted in distributions that differ markedly from the observations in Fig. 6, particularly for the monthly series. JRA55 and ERA-Interim generally obtained shape and scale values, respectively, that were closest to those of the daily observations, though CFSR and 20CR captured the daily autumn and daily winter wind scales, respectively. The ability of the reanalyzed wind series to capture the observed monthly parameters was more varied, with $\mathrm{R} 2$ and $20 \mathrm{CR}$ obtaining values that were comparable with those from the higherresolution reanalyses.

\section{c. Trends}

Observed daily wind speed trends from the homogenized series were negative over the period of record, as shown in Table 6 with each associated confidence interval $(\alpha=0.05)$. The observed regional average trend was $-0.057 \pm 0.044 \mathrm{~m} \mathrm{~s}^{-1}$ decade $^{-1}$. This observed trend over the 38 -yr period of interest, while significant, is smaller in magnitude than was found in previous studies which included the upper Midwest (Blunden and Arndt 2016; Pryor and Ledolter 2010; Pryor et al. 2009). Seasonally observed daily wind speed trends in spring $\left(-0.138 \pm 0.36 \mathrm{~m} \mathrm{~s}^{-1}\right.$ decade $\left.^{-1}\right)$, summer $\left(-0.203 \pm 0.272 \mathrm{~m} \mathrm{~s}^{-1}\right.$ decade $\left.^{-1}\right)$, autumn $\left(-0.267 \pm 0.364 \mathrm{~m} \mathrm{~s}^{-1}\right.$ decade $\left.^{-1}\right)$, and winter $(-0.277 \pm$ $0.371 \mathrm{~m} \mathrm{~s}^{-1}$ decade $^{-1}$ ) were strongly negative, though none were statistically significant. Stronger daily winds $(>50$ th percentile; not shown) exhibited larger, significant downward trends $\left(-0.068 \pm 0.007 \mathrm{~m} \mathrm{~s}^{-1}\right.$ decade $\left.^{-1}\right)$ than were found in weaker winds $(<50$ th percentile; not shown), which was not significant $(-0.028 \pm$ $0.031 \mathrm{~m} \mathrm{~s}^{-1}$ decade $^{-1}$ ).

While the spread of the trends overlap within the bounds of the confidence intervals (see Fig. 7), only the JRA55 wind series exhibited a statistically significant negative trend of $-0.11( \pm 0.024) \mathrm{m} \mathrm{s}^{-1}$ decade $^{-1}$. ERA-Interim, 20CR, and CFSR obtained negative daily wind speed trends, though they were not significant, while R2 and MERRA-2 exhibited nonsignificant, positive trends. CFSR exhibited nonsignificant, negative trends in all seasons, and all of the reanalyses obtained negative trends in the summer. None of the reanalyzed daily wind series captured the more pronounced decline in the stronger daily wind speeds ( $>50$ th percentile) relative to the weaker winds. Maps of the observed, station-based trends (Fig. 8) and those calculated for the reanalyses (Fig. 9) show the spatial differences between the relatively homogenous spread of the observed downward trends and the varying patterns that arose within the modeled wind series. The discrepancy between the observed and simulated trends has been attributed to several possible factors such as undocumented station inhomogeneities, changes in the local roughness caused by urbanization and land-use change, or the influences of climate change and teleconnections (Azorin-Molina et al. 2016; McVicar et al. 2012; Fu et al. 2011; Vautard et al. 2010; Wan et al. 2010). It is also notable that even when land surface wind data were included in the assimilation scheme of a reanalysis, insignificant trends in surface wind speeds have resulted, making the influence of factors external 
Distribution of Daily Wind Speeds
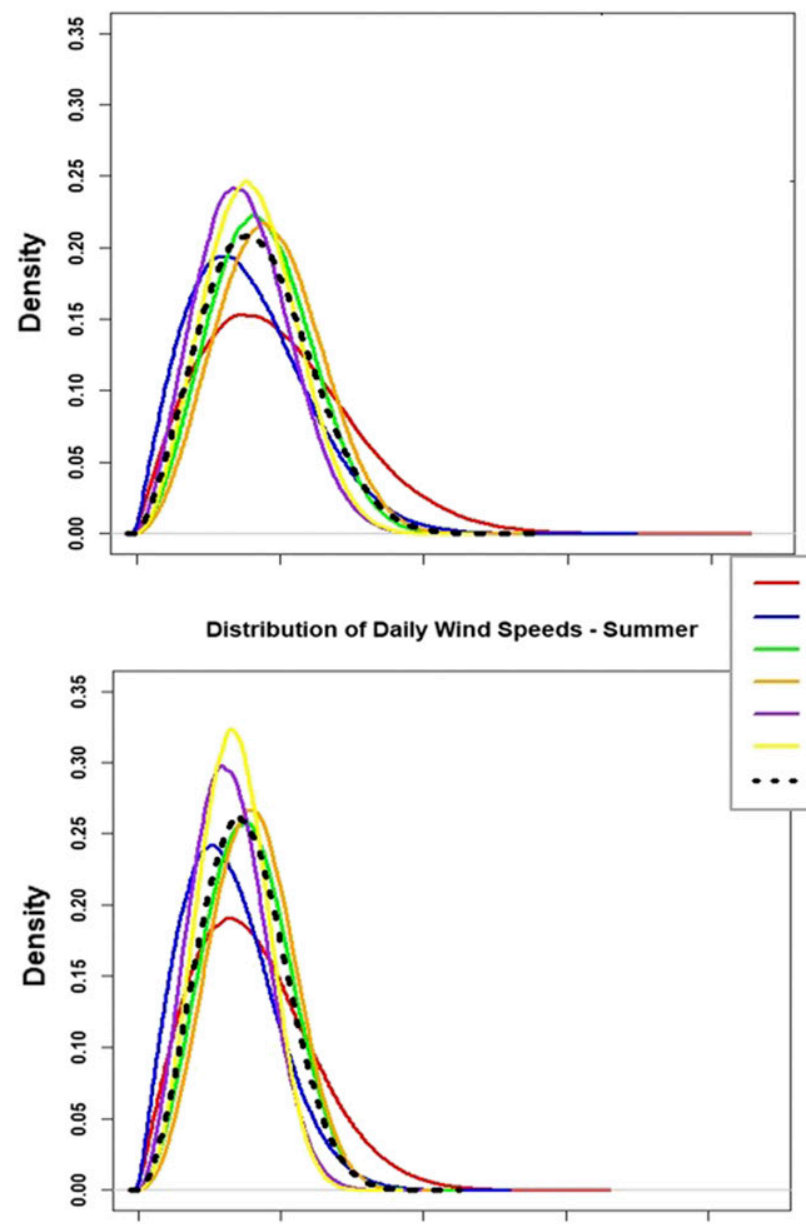

Distribution of Daily Wind Speeds - Winter

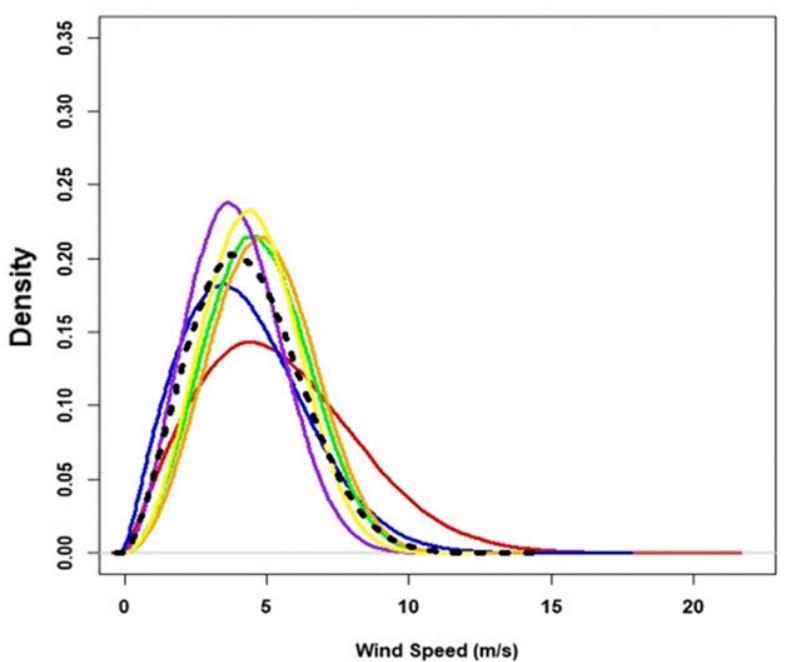

Distribution of Monthly Wind Speeds

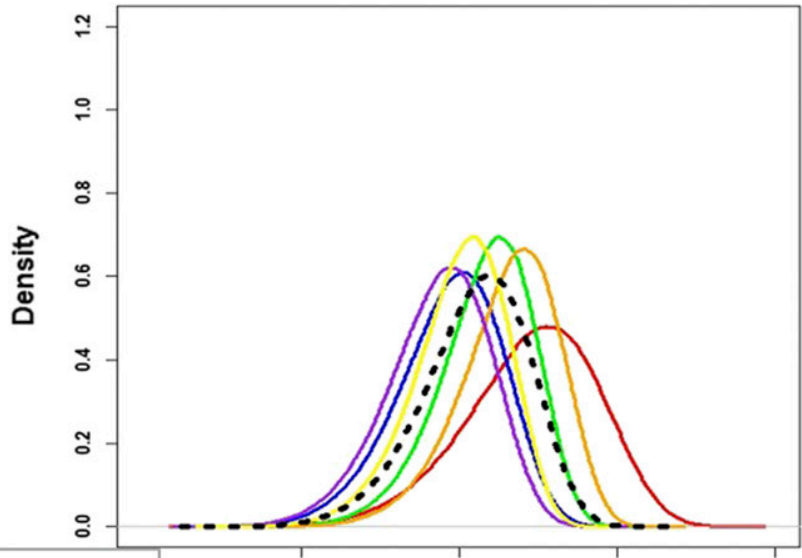

NCEP-R2

CIRES-20CR

ERA-Interim

Distribution of Monthly Wind Speeds - Summer

\section{MERRA}

JRA55

CFSR

Stations

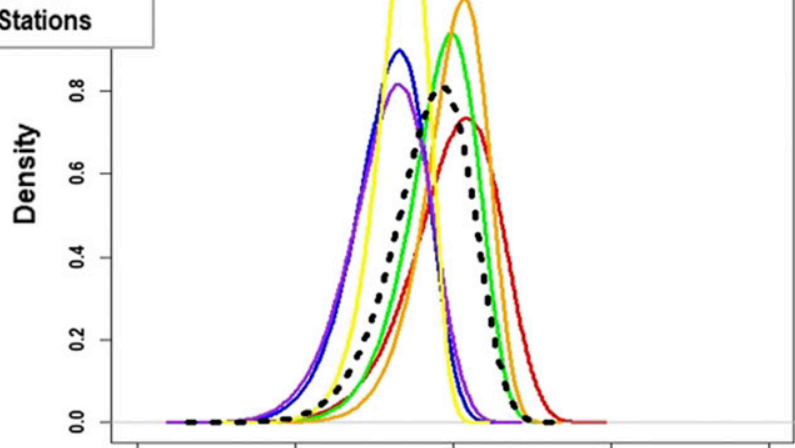

Distribution of Monthly Wind Speeds - Winter

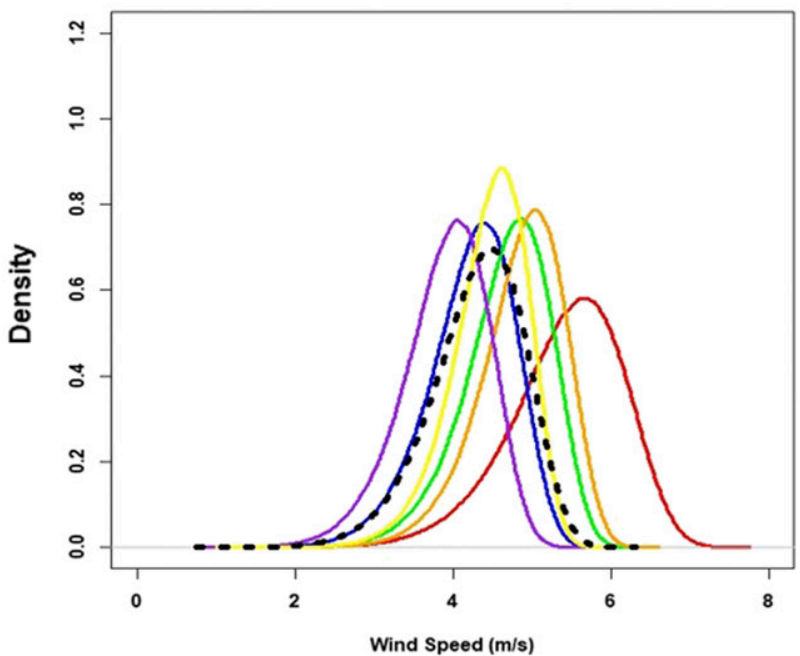

FIG. 6. Plots of the Weibull distributions that result from the shape and scale parameters found from the data in Table 5. Plots were generated using a random Weibull number generator and the respective parameters for the (left) daily and(right) monthly wind speed data for (top) all data, (middle) summer, and (bottom) winter. 
TABLE 6. Wind speed trends $\left(\mathrm{m} \mathrm{s}^{-1}\right.$ decade $\left.^{-1}\right) \pm 0.95$ confidence intervals over full period and for each daily seasonal subset of the observations and the reanalyzed wind series. Boldface values are significant $(\alpha=0.05)$, wherein the trends do not encompass 0 within their respective confidence intervals.

\begin{tabular}{lcrrrr}
\hline \hline & Full period of record & \multicolumn{1}{c}{ Spring } & \multicolumn{1}{c}{ Summer } & \multicolumn{1}{c}{ Autumn } \\
\hline Stations & $\mathbf{- 0 . 0 5 7} \pm \mathbf{0 . 0 4 4}$ & $-0.138 \pm 0.36$ & $-0.203 \pm 0.272$ & $-0.267 \pm 0.364$ & $-0.277 \pm 0.371$ \\
R2 & $0.022 \pm 0.040$ & $0.121 \pm 0.328$ & $-0.091 \pm 0.256$ & $0.165 \pm 0.326$ & $0.188 \pm 0.346$ \\
20CR & $-0.004 \pm 0.038$ & $0.063 \pm 0.304$ & $-0.161 \pm 0.237$ & $0.104 \pm 0.308$ & $-0.047 \pm 0.324$ \\
ERA-Interim & $-0.001 \pm 0.026$ & $0.052 \pm 0.207$ & $-0.162 \pm 0.176$ & $0.032 \pm 0.211$ & $0.093 \pm 0.220$ \\
MERRA-2 & $0.007 \pm 0.028$ & $0.089 \pm 0.235$ & $-0.055 \pm 0.178$ & $0.095 \pm 0.219$ & $0.022 \pm 0.228$ \\
JRA55 & $\mathbf{- 0 . 1 1 1} \pm \mathbf{0 . 0 2 4}$ & $\mathbf{- 0 . 3 1 6} \pm \mathbf{0 . 1 9 8}$ & $\mathbf{- 0 . 5 1 7} \pm \mathbf{0 . 1 5 2}$ & $\mathbf{- 0 . 4 8 9} \pm \mathbf{0 . 1 9 0}$ & $-\mathbf{0 . 4 1 5} \pm \mathbf{0 . 1 9 9}$ \\
CFSR & $-0.021 \pm 0.024$ & $-0.058 \pm 0.186$ & $-0.158 \pm 0.141$ & $-0.035 \pm 0.188$ & $-0.051 \pm 0.202$ \\
\hline
\end{tabular}

to the reanalyses more likely (Li et al. 2010; Mesinger et al. 2006).

\section{d. Spatial and temporal variations}

The upper Midwest is a relatively topographically homogenous region compared to areas of complex terrain like the Rocky Mountains, yet the changes in terrain and land cover throughout the region do have effects on wind speed. Much of the region overlaps with the Great Plains, though the northern and eastern portions partially encompass the Canadian shield and the western edges of the Great Lakes, respectively. Forests cover much of the northeastern quadrant, resulting in enhanced surface roughness and slower mean wind speeds. These variations were expressed in the reanalyses (Fig. 2) and could affect the accuracy of the reanalysis model. To assess the potential effects of these landscape variations, SGSs were split into three groups, the Canadian shield (station locations 6, 7, 8, and 17), the lake coast (station locations 4, 18, 27, and 29), and the plains (all locations not included in the other groups). Observed average wind speeds were found to vary significantly between the plains $\left(4.4 \mathrm{~m} \mathrm{~s}^{-1}\right)$, the Canadian shield $\left(3.3 \mathrm{~m} \mathrm{~s}^{-1}\right)$, and the coasts $\left(3.9 \mathrm{~m} \mathrm{~s}^{-1}\right)$. The skill scores were compared by calculating the difference of each region from the rest of the domain and tested for significance at the 0.95 confidence level using a Student's $t$ test. Variations between daily regional MD, MAE, and RMSE values followed a similar pattern and are represented by the MAE values in Table 7 . The ratio of the regional differences to the mean daily MAE values (reported in Table 3) are also given as percentages, indicating the relative size of the regional skill scores compared to the domain average. Differences between the regions and the domain were small and ranged from 0.01 to $0.48 \mathrm{~m} \mathrm{~s}^{-1}$ but significant ( $p$ values $<0.001$ ) for daily values, while monthly differences were generally smaller and found to be not significant. Regional differences as percentages of the domain-averaged daily MAE values ranged between $2.0 \%$ and $24.1 \%$ for the plains, $7.6 \%$ and $46.4 \%$ for the Canadian shield, and $0.1 \%$ and $48.5 \%$ for the lake coasts. JRA55 exhibited the largest regional differences for the Canadian shield $(46.4 \%)$ and the coasts $(48.5 \%)$, while CFSR exhibited the largest value for the plains $(24.1 \%)$. There were no significant regional variations in the daily correlations, with differences of up to only 0.03 , throughout the domain. Overall variations in regional skill scores, while significant in some cases, were small compared to the domain-averaged skill scores and were less than the uncertainty in the cup anemometer observations that covered most of the period of interest (Nadolski 1998).

Global and regional densities of assimilated observations within reanalysis models vary over time, as fewer instances and types of observations were available further back in the record. While the model parameters are consistent throughout the runtime of the simulation, the variations in data availability in space and time can differentially affect the accuracy of the reanalysis (Fujiwara et al. 2017). This is assessed by splitting the data into decadal periods (1980-89, 1990-99, 2000-09, 2010-16) for each reanalysis and comparing the skill scores and their relative percentage difference from the rest of the period of interest and is reported in Table 7. As with the spatial variations, significance was calculated using a $t$ test. While differences between specific decades and the average daily MAE values for the full period of interest were found to be significant ( $p$ values $<0.01$ ) for most decades and reanalyses, they ranged from 0.01 to $0.05 \mathrm{~m} \mathrm{~s}^{-1}$ and only reached $12.6 \%$, with most reanalyses exhibiting percentages below $5.0 \%$. Decadal differences in monthly MD, MAE, and RMSE were found to not be significant, as were the daily and monthly correlation variations between decades.

\section{Conclusions}

Comparisons of the reanalyses described here indicate an improvement in skill with increased resolution 


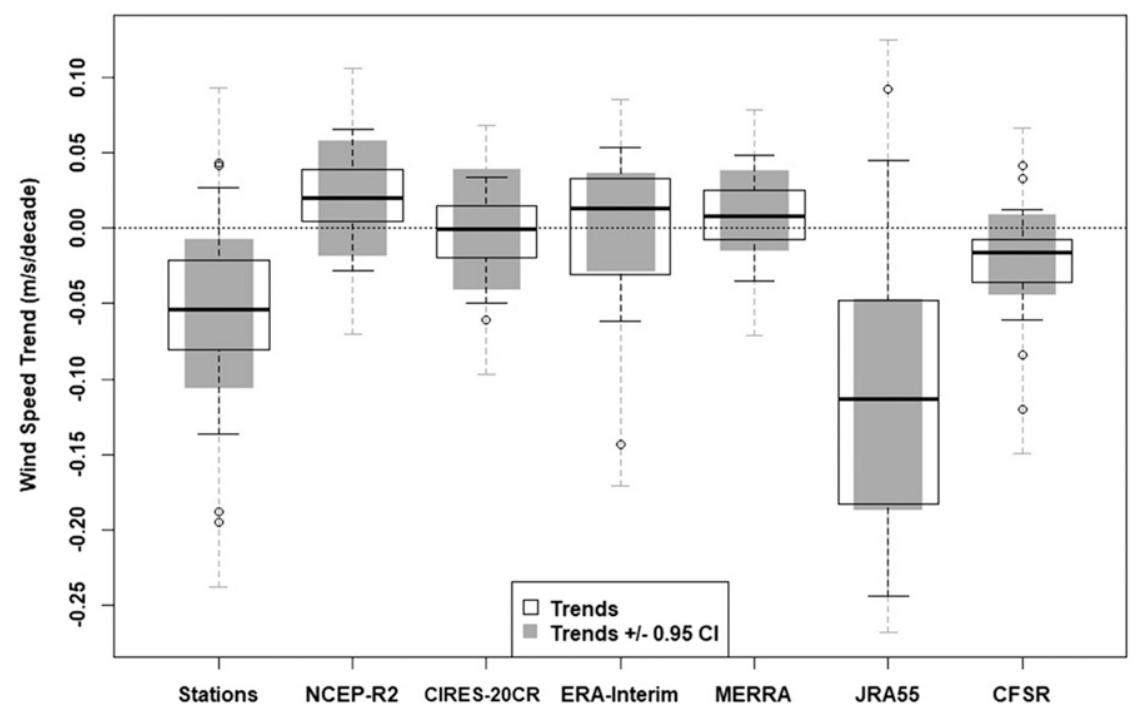

FIG. 7. Box plots of the station and SGS trends (black) and confidence intervals added and subtracted (gray), all in $\mathrm{m} \mathrm{s}^{-1}$ decade $^{-1}$. Black whiskers encompass all data to $1.5 \times \mathrm{IQR}$ (interquartile range). Gray whiskers encompass all data points.

and complexity. CFSR obtained the smallest overall daily errors while ERA-Interim obtained the lowest monthly overall scores, though CFSR, ERA-Interim, and MERRA-2 all had generally comparable error statistics and correlation values. MAE and RMSE values were consistent with those of previous studies that had assessed winds in regions overlapping the upper Midwest (Rose and Apt 2016; Decker et al. 2012). While the correlations between reanalyses and observations also improve with increased reanalysis resolution, the monthly correlations are smaller than the daily correlations. This finding ran counter to the findings of some past studies (Kaiser-Weiss et al. 2015) yet was supported by others (Toledo et al. 2015). Decker et al. (2012) found mixed results, with some locations exhibiting higher monthly correlations while some exhibited higher daily correlations. This may possibly stem from the SGSs where the long-term average seasonal cycle was small compared to the month-to-month variations.

Wind speed distribution parameters, in contrast, did not show a strong improvement with increased model resolution. Shape values from low-resolution output in $\mathrm{R} 2$ and 20CR were too high compared to observations, indicating that the wind variance was too large. Errors in the scale parameter indicated the overall sign of the bias in wind speeds between the reanalyses and the observations and was consistent with the MD values, with faster-than-observed winds from R2 and MERRA-2, slower-than-observed winds from 20CR and JRA55, and mixed errors from ERA-Interim and CFSR. Most of these mean differences were of the same sign as Lindsay et al. (2014), though MERRA-2 exhibited slower wind speeds in the Arctic, which would indicate that comparisons are regionally contingent.

Most reanalyzed wind fields exhibited no statistically significant or spatially coherent trend in daily speeds over the period of interest, in contrast to the significant negative trend exhibited by the homogenized wind speed

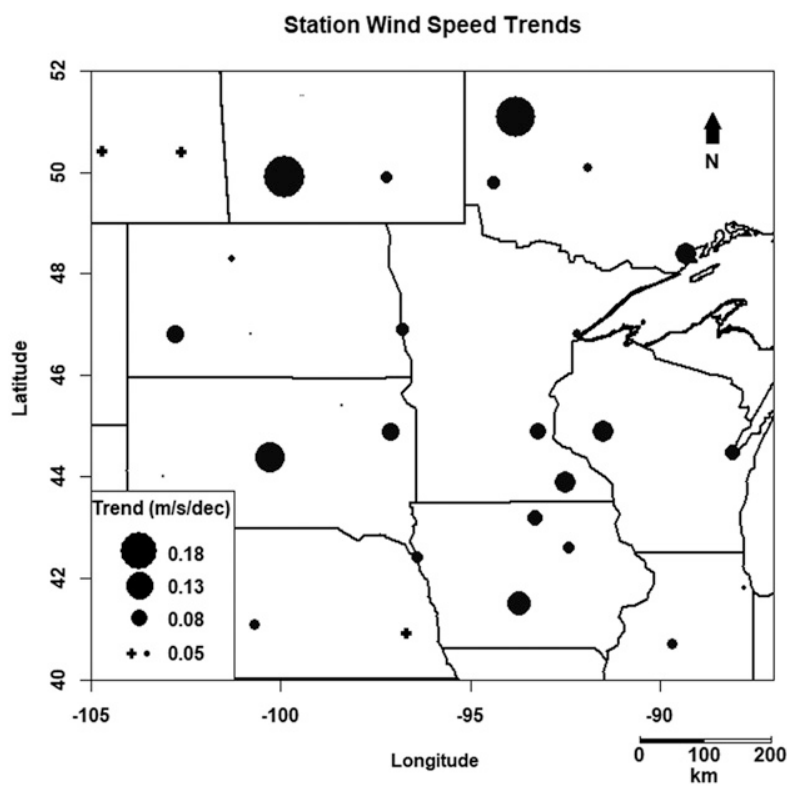

FIG. 8. Map of the observed trends in daily wind speeds $\left(\mathrm{m} \mathrm{s}^{-1}\right.$ decade $\left.^{-1}\right)$ at each station. Sizes indicate relative slope magnitudes. Dots indicate decreasing trends while crosses indicate increasing trends. 
Reanalyzed Wind Trend Maps
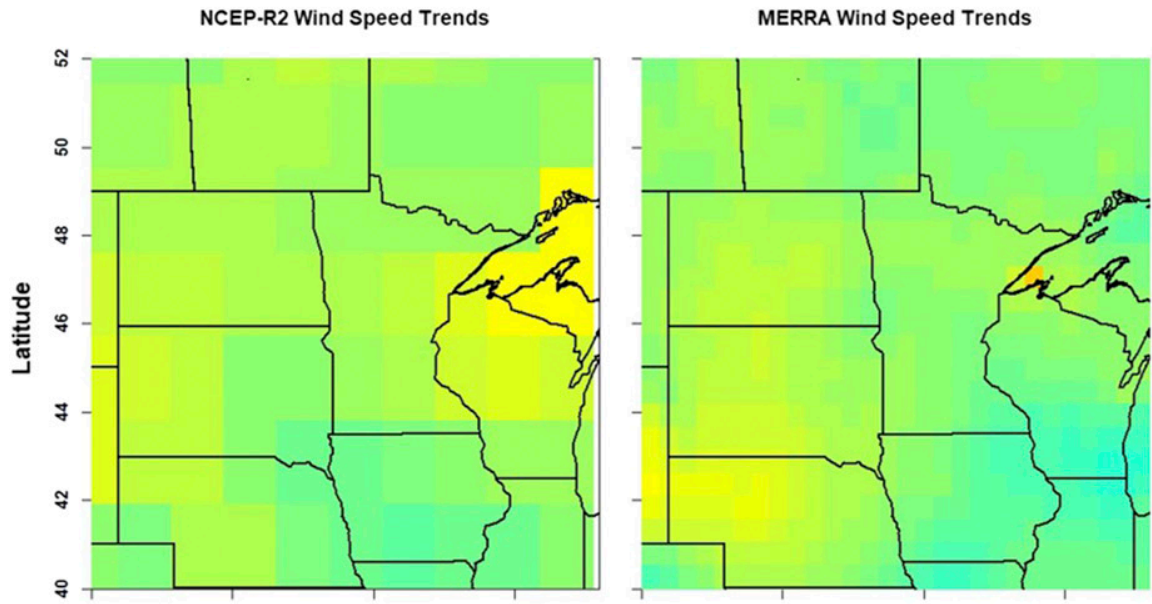

$\mathbf{N}$
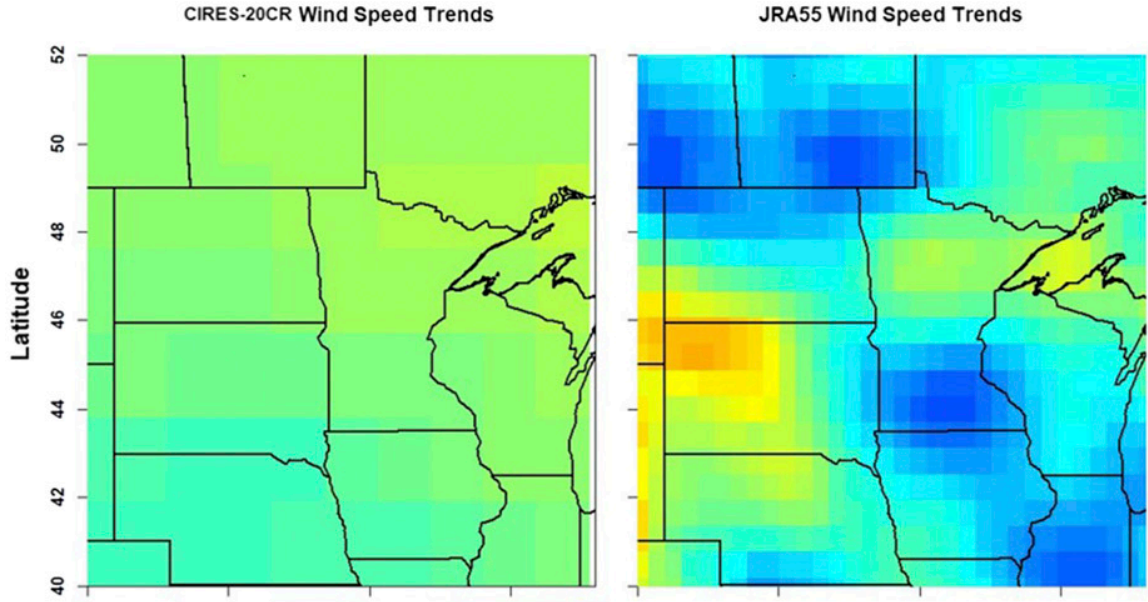

0.4
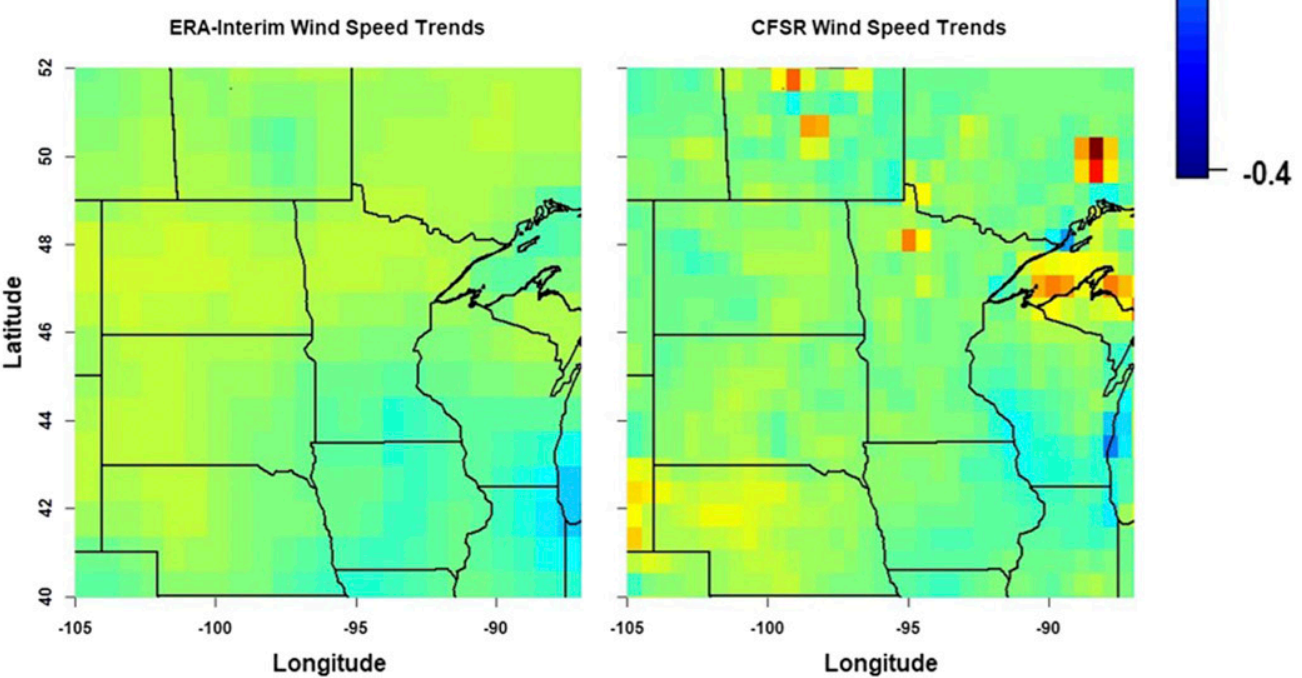

FIG. 9. Maps of the trends in daily wind speeds $\left(\mathrm{m} \mathrm{s}^{-1} \mathrm{decade}^{-1}\right)$ for the reanalyzed wind data. Cool colors indicate declining trends, and warm colors indicate increasing trends. 
TABLE 7. Spatiotemporal differences in the daily reanalyzed MAE scores. The MAE values are reported for each region within the domain of the upper Midwest and each decade within the period of interest. The difference between the region or time-period MAE value and that of the rest of the domain or period of interest is given in the parentheses as a percentage of the mean MAE values reported in Table 3. Italicized values are not statistically significant.

\begin{tabular}{|c|c|c|c|c|c|c|}
\hline & $\mathrm{R} 2$ & $20 \mathrm{CR}$ & ERA-Interim & MERRA-2 & JRA55 & CFSR \\
\hline \multicolumn{7}{|l|}{ Spatial } \\
\hline Plains & $1.53(1.3)$ & $1.37(21.9)$ & $0.91(18.4)$ & $0.87(-4.0)$ & $0.97(-2.0)$ & $0.86(24.1)$ \\
\hline Canadian shield & $1.44(-7.6)$ & $0.99(-21.9)$ & $0.66(-24.7)$ & $0.7(-33.0)$ & $0.68(-46.4)$ & $0.62(-20.4)$ \\
\hline Lake coasts & $1.58(6.3)$ & $1.18(0.1)$ & $0.84(6.3)$ & $1.11(36.9)$ & $1.3(48.5)$ & $0.71(-3.7)$ \\
\hline \multicolumn{7}{|l|}{ Temporal } \\
\hline 1980-89 & $1.52(-0.7)$ & $1.31(2.1)$ & $0.91(6.5)$ & $0.91(4.9)$ & $0.96(-2.4)$ & $0.84(5.8)$ \\
\hline 1990-99 & $1.54(1.1)$ & $1.29(0.1)$ & $0.88(1.9)$ & $0.9(3.4)$ & $0.91(-9.2)$ & $0.81(0.8)$ \\
\hline $2000-09$ & $1.52(-0.7)$ & $1.29(0.1)$ & $0.83(-5.7)$ & $0.85(-4.2)$ & $0.97(-1.0)$ & $0.77(-5.8)$ \\
\hline $2010-16$ & $1.53(0.2)$ & $1.27(-2.1)$ & $0.85(-2.7)$ & $0.85(-4.2)$ & $1.07(12.6)$ & $0.8(-0.8)$ \\
\hline
\end{tabular}

observations. JRA55 showed a statistically significant decrease in wind speed, though it was much larger in magnitude than the trend in the observations. Observed trends in the seasonal daily winds were also negative, though not significantly, and exhibited most of the decline in the upper 50th percentile, which was not replicated in the reanalyzed data. The homogenization process used in this analysis removed much of the trend in the raw wind observations, lending support to the possibility that regional and global wind trends are mostly the result of changes in station location or instrumentation, though such changes still did not fully explain the differences.

Applications utilizing reanalyzed wind data will need to account for the biases and uncertainties outlined in this study. Biases from the models can remain even when methods such as interpolation or MCP are applied and could cause costly errors in long-term wind energy estimates or cascading problems in hydrological or pollution models. The skill scores, distribution parameters, and trend analyses applied here provide some perspective on these issues. As the representation of wind speed distributions and long-term trends were generally evenly spread in their accuracy or were not well represented at all, any conclusions about the relative strength of the reanalyses comes down to their skill scores. ERA-Interim, MERRA-2, and CFSR tended to produce the most accurate wind speeds, with relatively similar MAE and RMSE values for all seasons. This would indicate that the higher-resolution models were more useful, as expected based on the capacity of the grids to resolve more processes, though JRA55 did not exhibit the same improvement in accuracy for having as high a resolution as these other reanalyses. Overall MD values were smallest for ERAInterim and CFSR, though seasonal values were quite varied, and no particular reanalysis performed consistently better than the others. R2 tended to exhibit larger MD values throughout the year than the other reanalyses. Operating at the same resolution, 20CR managed to perform about as well as the higherresolution models when compared according to the seasonal mean differences. Higher-resolution reanalyses also tended to produce the highest correlations, though this is also unsurprising given the comparison used here between the site-specific station data and the area-averaged grid cells. One rule of thumb proposed in previous research suggests that the daily data variance explained, which is calculated as the square of the correlation, should not fall below 0.7 if the reanalyzed dataset is to be considered useful (Liléo and Petrik 2011). From that perspective, the R 2 and 20CR models would not be considered accurate enough to be useful. Given the measures of error applied here, ERAInterim, MERRA-2, and CFSR models produced the most accurate results with smaller biases and comparable performance in the other metrics, though the decision on which is best to use would depend on the specific application. While the specific time step, period of interest, and the region being investigated are likely to affect considerations of reanalysis skill, for the datasets assessed here, decadal variations in skill were found to be small $\left(<0.05 \mathrm{~m} \mathrm{~s}^{-1}\right)$, while regional variations in skill were larger, but still relatively small $\left(0.5 \mathrm{~m} \mathrm{~s}^{-1}\right.$ or less), indicating that representations of wind within the region and over the period of interest are generally consistent. Future improvements in reanalyzed datasets can be expected to improve the representation of wind in the region, though it will still be necessary to account for model accuracy when using such datasets in future applications.

Acknowledgments. I would like to thank Dr. Katherine Klink for her help in reviewing the manuscript and adding her invaluable perspective. I received no specific funding for this work. 


\section{REFERENCES}

Azorin-Molina, C., and Coauthors, 2014: Homogenization and assessment of observed near-surface wind speed trends over Spain and Portugal, 1961-2011. J. Climate, 27, 3692-3712, https://doi.org/10.1175/JCLI-D-13-00652.1.

- J. Guijarro, T. Mcvicar, S. Vicente-Serrano, D. Chen, S. Jerez, and F. Espírito-Santo, 2016: Trends of daily peak wind gusts in Spain and Portugal, 1961-2014. J. Geophys. Res. Atmos., 121, 1059-1078, https://doi.org/10.1002/2015JD024485.

Bett, P. E., H. Thornton, and R. Clark, 2013: European wind variability over 140 yr. Adv. Sci. Res., 10, 51-58, https://doi.org/ 10.5194/asr-10-51-2013.

Bichet, A., M. Wild, D. Folini, and C. Schar, 2012: Causes for decadal variations of wind speed over land: Sensitivity studies with a global climate model. Geophys. Res. Lett., 39, L11701, https://doi.org/10.1029/2012GL051685.

Blunden, J., and D. Arndt, 2016: State of the Climate in 2015. Bull. Amer. Meteor. Soc., 97, Si-S275, https://doi.org/10.1175/ 2016BAMSStateoftheClimate.1.

Carta, J., S. Velázquez, and P. Cabrera, 2013: A review of measurecorrelate-predict (MCP) methods used to estimate long-term wind characteristics at a target site. Renew. Sustain. Energy Rev., 27, 362-400, https://doi.org/10.1016/j.rser.2013.07.004.

Cheng, X., and Coauthors, 2016: Implications of East Asian Summer and winter monsoons for interannual aerosol variations over central-eastern China. Atmos. Environ., 129, 218-228, https://doi.org/10.1016/j.atmosenv.2016.01.037.

Clark, R., P. Bett, H. Thornton, and A. Scaife, 2017: Skillful seasonal predictions for the European energy industry. Environ. Res. Lett., 12, 024002, https://doi.org/10.1088/1748-9326/aa57ab.

Compo, G., and Coauthors, 2011: The Twentieth Century Reanalysis Project. Quart. J. Roy. Meteor. Soc., 137, 1-28, https:// doi.org/10.1002/qj.776.

Decker, M., M. Brunke, Z. Wang, K. Sakaguchi, X. Zeng, and M. Bosilovich, 2012: Evaluation of the reanalysis products from GSFC, NCEP, and ECMWF using flux tower observations. J. Climate, 25, 1916-1944, https://doi.org/10.1175/ JCLI-D-11-00004.1.

Dee, D. P., and Coauthors, 2011: The ERA-Interim reanalysis: Configuration and performance of the data assimilation system. Quart. J. Roy. Meteor. Soc., 137, 553-597, https://doi.org/ 10.1002/qj.828.

Delignette-Muller, M. L., and C. Dutang, 2015: Fitdistrplus: An $\mathrm{R}$ package for fitting distributions. J. Stat. Software, 64, 1-34, https://doi.org/10.18637/jss.v064.i04.

Fisher, S., J. Schoof, C. Lant, and M. Therrell, 2013: The effects of geographical distribution on the reliability of wind energy. Appl. Geogr., 40, 83-89, https://doi.org/10.1016/j.apgeog.2013.01.010.

Fu, G., J. Yu, Y. Zhang, S. Hu, R. Ouyang, and W. Liu, 2011: Temporal variation of wind speed in China for 1961-2007. Theor. Appl. Climatol., 104, 313-324, https://doi.org/10.1007/ s00704-010-0348-x.

Fujiwara, M., and Coauthors, 2017: Introduction to the SPARC Reanalysis Intercomparison Project (S-RIP) and overview of the reanalysis systems. Atmos. Chem. Phys., 17, 1417-1452, https://doi.org/10.5194/acp-17-1417-2017.

Gelaro, R., and Coauthors, 2017: The Modern-Era Retrospective Analysis for Research and Applications, version 2 (MERRA-2). J. Climate, 30, 5419-5454, https://doi.org/10.1175/ JCLI-D-16-0758.1.

Gudmundsson, L., 2016: Qmap: Statistical transformations for post-processing climate model output, version1.0-4.
R package, https://cran.r-project.org/web/packages/qmap/ index.html.

Gunturu, U. B., and C. Schlosser, 2012: Characterization of wind power resource in the United States. Atmos. Chem. Phys., 12, 9687-9702, https://doi.org/10.5194/acp-12-9687-2012.

He, Y., A. Monahan, C. Jones, A. Dai, S. Biner, D. Caya, and K. Winger, 2010: Probability distributions of land surface wind speeds over North America. J. Geophys. Res., 115, D04103, https://doi.org/10.1029/2008JD010708.

Högström, U., and A. Smedman, 2004: Accuracy of sonic anemometers: laminar wind-tunnel calibrations compared to atmospheric in situ calibrations against a reference instrument. Bound.-Layer Meteor., 111, 33-54, https://doi.org/ 10.1023/B:BOUN.0000011000.05248.47.

Izumi, Y., and M. Barad, 1970: Wind Speed as Measured by Cup and Sonic Anemometers and Influenced by Tower Structure. J. Appl. Meteor., 9, 851-856, https://doi.org/10.1175/ 1520-0450(1970)009<0851:WSAMBC $>2.0 . \mathrm{CO} ; 2$.

Jung, J., and R. Broadwater, 2014: Current status and future advances for wind speed and power forecasting. Renewable Sustainable Energy Rev., 31, 762-777, https://doi.org/10.1016/ j.rser.2013.12.054.

Kaiser-Weiss, A. K., F. Kaspar, V. Heene, M. Borsche, D. G. H. Tan, P. Poli, A. Obregon, and H. Gregow, 2015: Comparison of regional and global reanalysis near-surface winds with station observations over Germany. Adv. Sci. Res., 12, 187198, https://doi.org/10.5194/asr-12-187-2015.

Kanamitsu, M., W. Ebisuzaki, J. Woollen, S. Yang, J. Hnilo, M. Fiorino, and G. Potter, 2002: NCEP-DOE AMIP-II Reanalysis (R-2). Bull. Amer. Meteor. Soc., 83, 1631-1643, https://doi.org/10.1175/BAMS-83-11-1631.

Kirchmeier, M., D. Lorenz, and D. Vimont, 2014: Statistical downscaling of daily wind speed variations. J. Appl. Meteor. Climatol., 53, 660-675, https://doi.org/10.1175/JAMC-D-13-0230.1.

Kirchner-Bossi, N., R. García-Herrera, L. Prieto, and R. Trigo, 2015: A long-term perspective of wind power output variability. Int. J. Climatol., 35, 2635-2646, https://doi.org/10.1002/ joc. 4161 .

Klink, K., 1999: Climatological mean and interannual variance of United States surface wind speed, direction and velocity. Int. J. Climatol., 19, 471-488, https://doi.org/10.1002/ (SICI)1097-0088(199904)19:5<471::AID-JOC367>3.0.CO;2-X. 2002: Trends and interannual variability of wind speed distributions in Minnesota. J. Climate, 15, 3311-3317, https://doi.org/ 10.1175/1520-0442(2002)015<3311:TAIVOW >2.0.CO;2.

— 2007: Atmospheric circulation effects on wind speed variability at turbine height. J. Appl. Meteor. Climatol., 46, 445456, https://doi.org/10.1175/JAM2466.1.

Kobayashi, S., and Coauthors, 2015: The JRA-55 Reanalysis: General specifications and basic characteristics. J. Meteor. Soc. Japan, 93, 5-48, https://doi.org/10.2151/jmsj.2015-001.

Kriesche, P., and A. Schlosser, 2014: The association of large-scale climate variability and teleconnections on wind energy resource over Europe and its intermittency. Energy Procedia, 59, 270277, https://doi.org/10.1016/j.egypro.2014.10.377.

Krogh, S., J. Pomeroy, and J. McPhee, 2015: Physically based mountain hydrological modeling using reanalysis data in Patagonia. J. Hydrometeor., 16, 172-193, https://doi.org/10.1175/JHM-D-130178.1 .

Krueger, O., F. Schenk, F. Feser, and R. Weisse, 2013: Inconsistencies between long-term trends in storminess derived from the 20CR reanalysis and observations. J. Climate, 26, 868-874, https://doi.org/10.1175/JCLI-D-12-00309.1. 
Kubik, M. L., D. Brayshaw, P. Coker, and J. Barlow, 2013: Exploring the role of reanalysis data in simulating regional wind generation variability over Northern Ireland. Renew. Energy, 57, 558-561, https://doi.org/10.1016/j.renene.2013.02.012.

Kumar, D., V. Mishra, and A. Ganguly, 2015: Evaluating wind extremes in CMIP5 climate models. Climate Dyn., 45, 441-453, https://doi.org/10.1007/s00382-014-2306-2.

Li, X., S. Zhong, X. Bian, and W. Heilman, 2010: Climate and climate variability of the wind power resources in the Great Lakes Region of the United States. J. Geophys. Res., 115, D18107, https://doi.org/10.1029/2009JD013415.

Liléo, S., and O. Petrik, 2011: Investigation on the use of NCEP/ NCAR, MERRA and NCEP/CFSR reanalysis data in wind resource analysis. European Wind Energy Conf. and Exhibition, Brussels, Belgium, EWEA, 181-185.

Lindsay, R., M. Wensnahan, A. Schweiger, and J. Zhang, 2014: Evaluation of seven different atmospheric reanalysis products in the Arctic. J. Climate, 27, 2588-2606, https://doi.org/10.1175/ JCLI-D-13-00014.1.

Lott, J. N., 2004: The quality control of the Integrated Surface Hourly database. 14th Conf. on Applied Climatology, Seattle, WA, Amer. Meteor. Soc., 7.8, https://ams.confex.com/ams/ 84Annual/techprogram/paper_71929.htm.

, and R. Baldwin, 2002: The FCC Integrated Surface Hourly database, a new resource of global climate data. 13th Symp. on Global Change and Climate Variations, Orlando, FL, Amer. Meteor. Soc., 6.2, https://ams.confex.com/ams/annual2002/ webprogram/Paper27792.html.

McVicar, T. R., and Coauthors, 2012: Global review and synthesis of trends in observed terrestrial near-surface wind speeds: Implications for evaporation. J. Hydrol., 416-417, https://doi.org/10.1016/j.jhydrol.2011.10.024.

Mesinger, F., and Coauthors, 2006: North American Regional Reanalysis. Bull. Amer. Meteor. Soc., 87, 343-360, https:// doi.org/10.1175/BAMS-87-3-343.

Mizukami, N., and Coauthors, 2016: Implications of the methodological choices for hydrologic portrayals of climate change over the contiguous United States: Statistically downscaled forcing data and hydrologic models. J. Hydrometeor., 17, 73-98, https://doi.org/10.1175/JHM-D-14-0187.1.

Nadolski, V., 1998: Automated Surface Observing System (ASOS) user's guide. NOAA Doc., 74 pp., https://www.weather.gov/ media/asos/aum-toc.pdf.

Olauson, J., and M. Bergkvist, 2015: Modelling the Swedish wind power production using MERRA reanalysis data. Renewable Energy, 76, 717-725, https://doi.org/10.1016/j.renene.2014.11.085.

Parker, W. S., 2016: Reanalyses and observations: What's the difference? Bull. Amer. Meteor. Soc., 97, 1565-1572, https:// doi.org/10.1175/BAMS-D-14-00226.1.

Pirazzoli, P. A., and A. Tomasin, 2003: Recent near-surface wind changes in the central Mediterranean and Adriatic areas. Int. J. Climatol., 23, 963-973, https://doi.org/10.1002/joc.925.

Pryor, S. C., and J. Ledolter, 2010: Addendum to "Wind speed trends over the contiguous United States." J. Geophys. Res., 115, D10103, https://doi.org/10.1029/2009JD013281.

_- and Coauthors, 2009: Wind speed trends over the contiguous United States. J. Geophys. Res., 114, D14105, https://doi.org/ 10.1029/2008JD011416.

, R. J. Barthelmie, and J. T. Schoof, 2012: Past and future wind climates over the contiguous USA based on the North American Regional Climate Change Assessment Program model suite. J. Geophys. Res., 117, D19119, https://doi.org/ 10.1029/2012JD017449.
R Core Team, 2017: R: A language and environment for statistical computing. R Foundation for Statistical Computing, https:// www.R-project.org/.

Rienecker, M., and Coauthors, 2011: MERRA: NASA's Modern-Era Retrospective Analysis for Research and Applications. J. Climate, 24, 3624-3648, https://doi.org/10.1175/JCLI-D-11-00015.1.

Rose, S., and J. Apt, 2015: What can reanalysis data tell us about wind power? Renewable Energy, 83, 963-969, https://doi.org/ 10.1016/j.renene.2015.05.027.

$\longrightarrow$, and — 2016: Quantifying sources of uncertainty in reanalysis derived wind speed. Renewable Energy, 94, 157-165, https://doi.org/10.1016/j.renene.2016.03.028.

Rust, H., O. Mestre, and V. Venema, 2008: Fewer jumps, less memory: Homogenized temperature records and long memory. J. Geophys. Res., 113, 1-8, https://doi.org/10.1029/2008JD009919.

Saha, S., and Coauthors, 2010: The NCEP Climate Forecast System Reanalysis. Bull. Amer. Meteor. Soc., 91, 1015-1057, https:// doi.org/10.1175/2010BAMS3001.1.

Schoof, J. T., and S. Pryor, 2014: Assessing the fidelity of AOGCMsimulated relationships between large-scale modes of climate variability and wind speeds. J. Geophys. Res. Atmos., 119, 9719-9734, https://doi.org/10.1002/2014JD021601.

Sharp, E., P. Dodds, M. Barrett, and C. Spataru, 2015: Evaluating the accuracy of CFSR reanalysis hourly wind speed forecasts for the UK, using in situ measurements and geographical information. Renewable Energy, 77, 527-538, https://doi.org/ 10.1016/j.renene.2014.12.025.

Smith, A., L. Neal, and R. Vose, 2011: The Integrated Surface Database: Recent developments and partnerships. Bull. Amer. Meteor. Soc., 92, 704-708, https://doi.org/10.1175/2011BAMS3015.1.

Smits, A., A. Tank, and G. Können, 2005: Trends in storminess over the Netherlands, 1962-2002. Int. J. Climatol., 25, 13311344, https://doi.org/10.1002/joc.1195.

Toledo, C., R. Chávez-arroyo, L. Loera, and O. Probst, 2015: A surface wind speed map for Mexico Based on NARR and observational data. Meteor. Appl., 22, 666-678, https://doi.org/ $10.1002 /$ met.1500.

Vanvyve, E., L. Monache, A. Monaghan, and J. Pinto, 2015: Wind resource estimates with an analog ensemble approach. Renewable Energy, 74, 761-773, https://doi.org/10.1016/j.renene.2014.08.060.

Vautard, R., J. Cattiaux, P. Yiou, J. Thépaut, and P. Ciais, 2010: Northern Hemisphere atmospheric stilling partly attributed to an increase in surface roughness. Nat. Geosci., 3, 756-761, https://doi.org/10.1038/ngeo979.

Wan, H., X. Wang, and V. Swail, 2010: Homogenization and trend analysis of Canadian near-surface wind speeds. J. Climate, $\mathbf{2 3}$ 1209-1225, https://doi.org/10.1175/2009JCLI3200.1.

Wang, L., Y. Feng, R. Chan, and V. Isaac, 2016: Inter-comparison of extra-tropical cyclone activity in nine reanalysis datasets. Atmos. Res., 181, 133-153, https://doi.org/10.1016/j.atmosres.2016.06.010.

Wieringa, J., 1980: A revaluation of the Kansas mast influence on measurements of stress and cup anemometer overspeeding. Bound.-Layer Meteor., 18, 411-430, https://doi.org/10.1007/ BF00119497.

Yu, L., S. Zhong, X. Bian, and W. Heilman, 2015: Temporal and spatial variability of wind resources in the United States as derived from the Climate Forecast System Reanalysis. J. Climate, 28, 11661183, https://doi.org/10.1175/JCLI-D-14-00322.1.

,,,--- and,- 2016 : Climatology and trend of wind power resources in China and its surrounding regions: A revisit using Climate Forecast System Reanalysis data. Int J. Climatol., 36, 2173-2188, https://doi.org/10.1002/joc.4485. 